DEMOGRAPHIC RESEARCH

VOLUME 32, ARTICLE 21, PAGES 621-656 PUBLISHED 3 MARCH 2015

http://www.demographic-research.org/Volumes/Vol32/21/

DOI: 10.4054/DemRes.2015.32.21

Research Article

Europe-wide fertility trends since the 1990s: Turning the corner from declining first birth rates

Marion Burkimsher

(C) 2015 Marion Burkimsher.

This open-access work is published under the terms of the Creative Commons Attribution NonCommercial License 2.0 Germany, which permits use, reproduction \& distribution in any medium for non-commercial purposes, provided the original author(s) and source are given credit.

See http://creativecommons.org/licenses/by-nc/2.0/de/ 


\section{Table of Contents}

$\begin{array}{lll}1 & \text { Introduction } & 622\end{array}$

$2 \quad$ Literature review $\quad 623$

3 Data $\quad 624$

3.1 Why examine just first birth fertility rates?

$3.2 \quad$ What period to examine? 626

$\begin{array}{lll}3.3 & \text { Choice of study window } & 627\end{array}$

$\begin{array}{lll}3.4 & \text { Data source } & 627\end{array}$

$4 \quad$ Analyses $\quad 630$

$4.1 \quad$ Overview of TFR1 trends 630

4.2 Changes in height and width of the fertility curve 631

4.3 Source of change in the width of the fertility curve 636

4.4 Changes in mean age at first birth 644

4.5 Comparison of cohort and period trends 644

4.6 Is change in the parity composition part of the explanation? 649

5 Conclusion $\quad 653$

6 Acknowledgements $\quad 654$

$\begin{array}{ll}\text { References } & 655\end{array}$ 


\title{
Europe-wide fertility trends since the 1990s: Turning the corner from declining first birth rates
}

\author{
Marion Burkimsher ${ }^{1}$
}

\begin{abstract}
BACKGROUND

In the period 1995-2002 there was a change in trajectory from decline to rise in first birth fertility rates across Europe.
\end{abstract}

\section{OBJECTIVE}

A number of previous studies have looked at the demographic causes of the transition. This study evaluates their conclusions by analysing a comprehensive set of indicators for fifteen countries with data in the Human Fertility Database.

\section{METHODS}

Comparisons are made between the four years before and after the fertility trough, to discover what changed between these two periods.

\section{RESULTS}

In the period before the trough, peak age-specific fertility rates were falling; these tended to stabilise after the year of minimum fertility. The width of the fertility curve, however, was already widening in the 1990s, and this trend continued. The transition from fall to rise in TFR1 occurred when the increase in the width of the curve more than compensated for any further falls in peak rates; this explanation is valid for countries in both Eastern and Western Europe. The increasing width of the fertility curve was caused by two factors: the decline in young (pre-modal) fertility slowed, whilst the rise in older (post-modal) fertility accelerated. For some countries, a rise in underlying cohort rates also contributed to the rise in period rates. The likelihood of childless women entering motherhood also rose in some but not all countries.

\section{CONCLUSIONS}

During the 1990s, women were postponing first births across Europe. A rebound took place for several reasons, with the overarching driver being the strong rise in late fertility.

\footnotetext{
${ }^{1}$ Independent researcher affiliated to the University of Lausanne, Switzerland.

E-Mail: drmarionb@gmail.com.
} 


\section{COMMENTS}

In some countries the steep rise in late fertility had an unexpected and paradoxical effect on postponement rates (defined as the year-on-year increase in mean age at first birth). Recuperation at post-modal ages of postponed first births caused an acceleration in 'postponement' rates, as defined by this metric.

\section{Introduction}

The purpose of this study is to look at the 'mechanical' or 'demographic' causes of the transition from decline to rise in period fertility rates which occurred across Europe between 1995 and 2003. Several recent studies have also examined this question, in particular Frejka (2012), Bongaarts and Sobotka (2012), and, for Australia, McDonald and Kippen (2011). Their papers applied several quantitative measures and analysed different sets of countries. This study presents a comprehensive set of indices based on one data source (the Human Fertility Database) in order to test the conclusions reached in these previous studies.

For reasons discussed further below, only rates for first births are studied. This restriction offers the potential for a 'cleaner' interpretation of the trends, although limiting the number of countries to only those with fertility data by biological birth order.

The 15 countries studied cover both Western and Eastern Europe, regions which had, until recently, quite different fertility patterns. Since 1989, however, the early and almost universal entry into motherhood seen in the ex-communist states has been transforming into the western model of a much wider span of age at first birth and a greater likelihood that a woman will remain childless. The Western European countries covered in this report are Austria, Finland, the Netherlands, Norway, Portugal, Sweden, and Switzerland. The Eastern European countries are Bulgaria, the Czech Republic, Estonia, Hungary, Lithuania, Russia, Slovakia, and Slovenia. This dichotomy reflects the classification used by Frejka (2012).

A critical question is whether the transition was due solely to changes in the timing of fertility - a decline in postponement or 'tempo' effects - or whether there was also a 'quantum' element - a rise in cohort fertility levels. As more than a decade has now passed since the fertility troughs, we can now make a fair assessment of the underlying cohort trends.

Finally, we examine whether the rise in first birth fertility rates was, at least partially, due to a 'bulge' of childless women who had previously postponed childbearing. We use a probability measure, the parity adjusted total fertility rate for 
first births (PATFR1), to investigate whether the likelihood of a childless woman having a first child changed over time.

\section{Literature review}

A primary aim of this paper is to critically appraise the results and conclusions of the specific papers cited below, using newly analysed data.

Bongaarts and Sobotka (2012) proposed two alternative models ('period-driven' and 'cohort-driven') to describe the transition from decline to rise and make specific predictions about changes in height of the fertility curve (mode) and its width (standard deviation of mean age at first birth, MAB1). They analysed data from the Czech Republic, the Netherlands, Spain, and Sweden (looking at the age-specific fertility rates of first births, ASFR1), plus Denmark, France, Italy, and the UK (all birth orders combined). They conclude that there were significant period effects in all the countries studied, as evidenced primarily by rising peak (modal) rates in the post-trough period, but that cohort effects were also significant in the Czech Republic and possibly Spain. Their models are tested and discussed in section 4.2.

Frejka (2012) compared the trends for 'young' fertility with 'older' fertility and proposed a four-phase postponement and recuperation model to explain fertility dynamics, using data mainly from Denmark, Norway, Belgium, the Netherlands, and New Zealand. In Phase 1, young women (aged 15-28) postpone childbearing, whilst fertility rates for older women (aged 29-49) are stable; TFRs fall. In Phase 2, TFRs start to rise as older cohorts recuperate births and this exceeds any continuing postponement of young women. In Phase 3, young fertility stabilises whilst older fertility continues to increase, boosting the TFR rise. In the final phase, postponement and recuperation cease and period and cohort rates become equal. Western European countries are at a later phase of transition than Eastern European countries. Frejka concludes that although period fertility rates rose in the decade 2000-2010, cohort rates fell. His model is discussed and investigated in sections 4.3 and 4.5.

McDonald and Kippen (2011) developed a comprehensive methodology to describe and forecast births based on parity distribution data and age-specific fertility trends, plus duration since previous birth. Impressively, their method could predict the turning point in the TFR that actually occurred in 2001 in Australia. The fall in TFR from 1992 to 2001 was seen to stem from a decline in fertility rates of women under 30, which was larger than the rise in fertility rates of women over 30. From 2001 onwards this situation reversed. The TFR rose because women at older ages were 'recuperating' their previously 'postponed' births, whilst younger women ceased delaying their births any further. For Australia, McDonald and Kippen calculated that period and underlying 
cohort fertility in 2006 were almost identical at close to 1.8 and the tempo effect, which deflates period rates, had fallen to zero. From Frejka's perspective, it would seem that Australia had now reached Phase 4, with period/cohort comparability.

Lesthaeghe and Permanyer (2014) recently completed a comprehensive study of early (ages 20-29) and later (ages 30-39) fertility covering 28 European countries. Since 2000, early fertility has generally been stable in Western Europe, whilst in some Eastern European countries there has been an on-going decline. However, all countries without exception have seen a rise in later fertility.

Goldstein, Sobotka, and Jasilioniene (2009) drew a similar conclusion to the authors above, that it is the stabilisation of young fertility (below age 28) together with a continuous increase in late fertility $(>28)$ that has produced much of the observed rise in TFR. The countries with the highest fertility rates (of the 'low-fertility' countries) are those in which tempo effects have almost disappeared. They also showed that the rate of postponement through the transition is a complex curve (Appendix 6 of their paper). The rise in later childbearing (= 'recuperation') raises the mean age at first birth; but if this is interpreted as on-going 'postponement', and adjusted for by the traditional Bongaarts-Feeney method, it will over-compensate the period rates when trying to estimate cohort rates. This is investigated further in section 4.4.

All the previously cited papers have considered that cohort fertility has remained stable or continued a downward trend. A recent paper by Myrskylä, Goldstein, and Cheng (2013) challenges this, as well as describing a simple modelling procedure for projecting cohort rates. For many of the countries included in our analysis they see indications of rising cohort rates. Their work considers all birth orders combined: in our analysis (section 4.5) we examine whether there are also significant quantum changes for first birth rates.

\section{Data}

This section describes the data sources used and the choices made as to which data to analyse.

\subsection{Why examine just first birth fertility rates?}

Kohler, Billari, and Ortega (2006:41), in explaining lowest-low fertility levels, considered that it was not changes in first birth rates that were the cause, but rather that it was "a low progression probability after the first child (but not particularly low levels of first-birth childbearing)". However, in contrast, more recent studies reach the 
consensus is that it was a rise in first, rather than higher order, births that, at least initially, caused the TFR to start rising. Bongaarts and Sobotka (2012:87-88) state that "increases in TFR were mostly due to increases at birth orders one and two while TFRs at higher orders were flat or declining". A more nuanced conclusion was reached by Goldstein, Sobotka, and Jasilioniene (2009): they saw that in most countries in southern and central Europe it was an increase in first-order birth rates that drove the recovery in TFR, whilst in other ex-communist states the increase in second and higher-order birth rates was at least as important.

The first question we address is whether the rise in total fertility rate started at the same time as the rise in the fertility rate for first births - or did the rise in TFR1 happen first, and hence could be seen as the 'initiator' of the rise in TFR? We might intuitively expect that the first birth rate would start to rise first, followed by the rate for second and then higher-order births. Table 1 shows that in all countries the rise in TFR1 commenced either before or at the same time as the rise in TFR2, and the combined TFR also started rising either after or at the same time as the start of the rise in TFR1: this indicates that the impetus for the rise in TFR came, at least initially, from a rise in TFR1.

Table 1: Years of fertility rate minima 1995-2003

\begin{tabular}{|c|c|c|c|c|c|c|c|c|}
\hline Country & $\begin{array}{c}\text { TFR1 } \\
\text { min }\end{array}$ & $\begin{array}{c}\text { TFR2 } \\
\text { min }\end{array}$ & $\begin{array}{l}\text { TFR } \\
\text { min }\end{array}$ & $\begin{array}{c}\text { TFR1 min before }<, \\
\text { or same as = } \\
\text { TFR min }\end{array}$ & $\begin{array}{l}\text { Years TFR min } \\
\text { later than } \\
\text { TFR1 min }\end{array}$ & $\begin{array}{c}\text { PATFR1 } \\
\min \end{array}$ & $\begin{array}{c}\text { TFR1 min before <, } \\
\text { or same as = } \\
\text { PATFR1 } \mathrm{min}\end{array}$ & $\begin{array}{l}\text { Years PATFR1 min } \\
\text { later than } \\
\text { TFR1 min }\end{array}$ \\
\hline Austria & 1999 & 2001 & 2001 & $<$ & 2 & 2001 & $<$ & 2 \\
\hline Bulgaria & 1997 & 1997 & 1997 & $=$ & 0 & 2002 & $<$ & 5 \\
\hline Czech Rep & 1996 & 2002 & 1999 & $<$ & 3 & 2001 & $<$ & 5 \\
\hline Estonia & 1998 & 1998 & 1998 & $=$ & 0 & 2001 & $=$ & 3 \\
\hline Finland & 1998 & 2002 & 1998 & $=$ & 0 & 2002 & $<$ & 4 \\
\hline Hungary & 1999 & 2004 & 2003 & $<$ & 4 & 2003 & $<$ & 4 \\
\hline Lithuania & 2002 & 2002 & 2002 & $=$ & 0 & 2003 & $<$ & 1 \\
\hline Netherlands & 1995 & 1996 & 1996 & $<$ & 1 & 1995 & $=$ & 0 \\
\hline Norway & 2002 & 2002 & 2002 & $=$ & 0 & 2002 & $=$ & 0 \\
\hline Portugal & 1995 & 1995 & 1995 & $=$ & 0 & 1995 & $=$ & 0 \\
\hline Russia & 1999 & 1999 & 1999 & $=$ & 0 & 1999 & $=$ & 0 \\
\hline Slovakia & 2001 & 2002 & 2002 & $<$ & 1 & 2001 & $=$ & 0 \\
\hline Slovenia & 2001 & 2002 & 2003 & $<$ & 2 & 2001 & $=$ & 0 \\
\hline Sweden & 1998 & 2000 & 1999 & $<$ & 1 & 1998 & $=$ & 0 \\
\hline Switzerland & 1995 & 2003 & 2001 & $<$ & 6 & $2001 ?$ & $<$ & $6 ?$ \\
\hline
\end{tabular}

Note: PATFR1 for Switzerland unavailable prior to 2000; year of PATFR1 minimum estimated 
We decomposed the rise in TFR after the trough into the changes in the TFR1, TFR2, and TFR3 + rates for the four years after the TFR minimum (Figure 1). In this period around $70 \%$ of the increase in TFR, on average, came from an increase in the TFR1. Only in Estonia was the rise in TFR2 greater than the rise in TFR1. In subsequent years the rise in rates for second-order births became more widespread. Changes in TFR3 + have had only a small impact on overall trends.

Figure 1: Increases in the TFR for the period 4 years after the fertility trough, decomposed by birth order

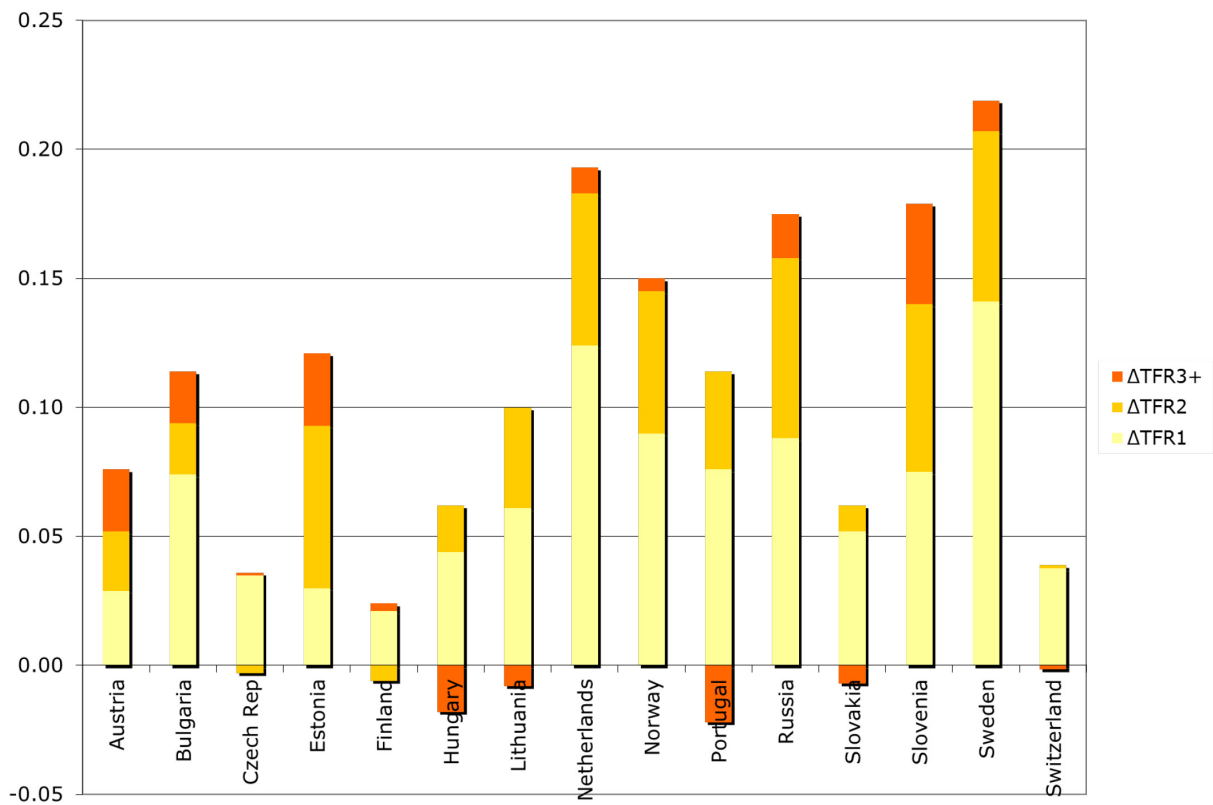

It is for these reasons that we feel the focus on trends in TFR1 is justified. Further analysis of trends in fertility rates of higher-order births would be a valuable future research strand.

\subsection{What period to examine?}

Frejka (2012) looks at the trends in fertility rates from the 1980s and finds that there was a trough for the Western European countries in the early 1980s followed by a 
subsequent rise. Peak rates were reached in the period 1988-1991, after which declines again set in (Figure 2). The falls seen in Western Europe during the 1990s paralleled those seen in Eastern Europe, although they were considerably less intense. A second trough then occurred in the period 1995-2002. For three of the Western countries we studied, the first trough was deeper than the second (Finland, the Netherlands, and Norway); for Switzerland it was practically the same; but in the other three countries the second trough was deeper than the first (Austria, Portugal, and Sweden).

We focus on the troughs of 1995-2002 for all the countries across Europe; we then compare the Eastern and Western countries to see if there are significant differences in the processes between these two regions. More work could usefully be done in examining and explaining the trough, peak, and decline of period fertility in Western Europe from the early 1980s to mid-1990s.

\subsection{Choice of study window}

To compare the trends in the period immediately before and immediately after the trough we had to decide on the duration to be considered each side of the trough. We looked at three-, four-, and five-year durations. The problem of using too short a window is that the trough for some countries was ill-defined and extended over several years, with minor rises and falls in that period. However, we wanted to focus on what the 'trigger' was for the transition from decline to rise in fertility rates. We finally settled on using four years for our comparison, which gave sufficient focus on the 'moment' of transition without suffering from the vagaries of short-term insignificant fluctuations. With a window of four years we found we could make generalisations that worked across all countries.

\subsection{Data source}

One primary data source, the Human Fertility Database (www.humanfertility.org), was used for all the analyses presented in this report. For Switzerland, this was supplemented by data in the Human Fertility Collection (Burkimsher 2011), as this includes modelled birth order data for the years prior to 1998. In our study there is a preponderance of Scandinavian/Baltic countries (Finland, Norway, Sweden, Estonia, and Lithuania) and a paucity of Southern European countries (only Portugal is represented). Unfortunately, the large Western European countries of Germany, the UK, France, and Italy do not have birth-order-specific data in the HFD pertaining to the period under study, and so could not be included. 
Figure 2a: Trends in TFR1 1980-2009: Western European countries

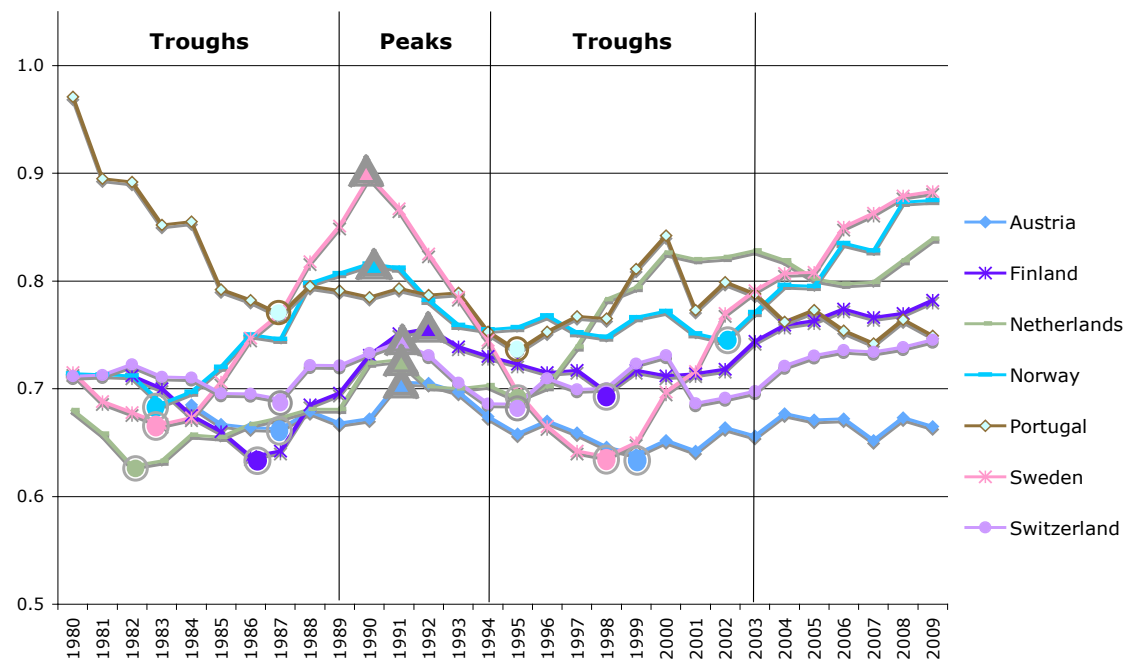

Circles indicate years of troughs, triangles are years of peaks

Figure 2b: Summary of changes in TFR1 in the 4 years before and 4 years after the TFR1 minima of 1995-2002: Western European countries

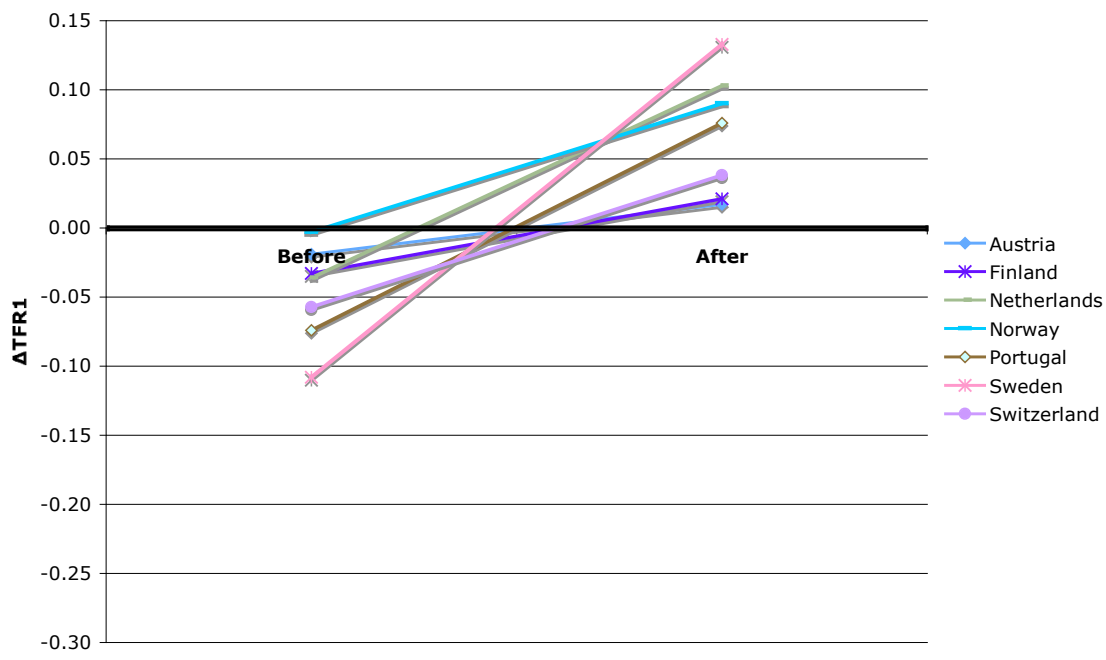


Figure 2c: Trends in TFR1 1980-2009: Eastern European countries

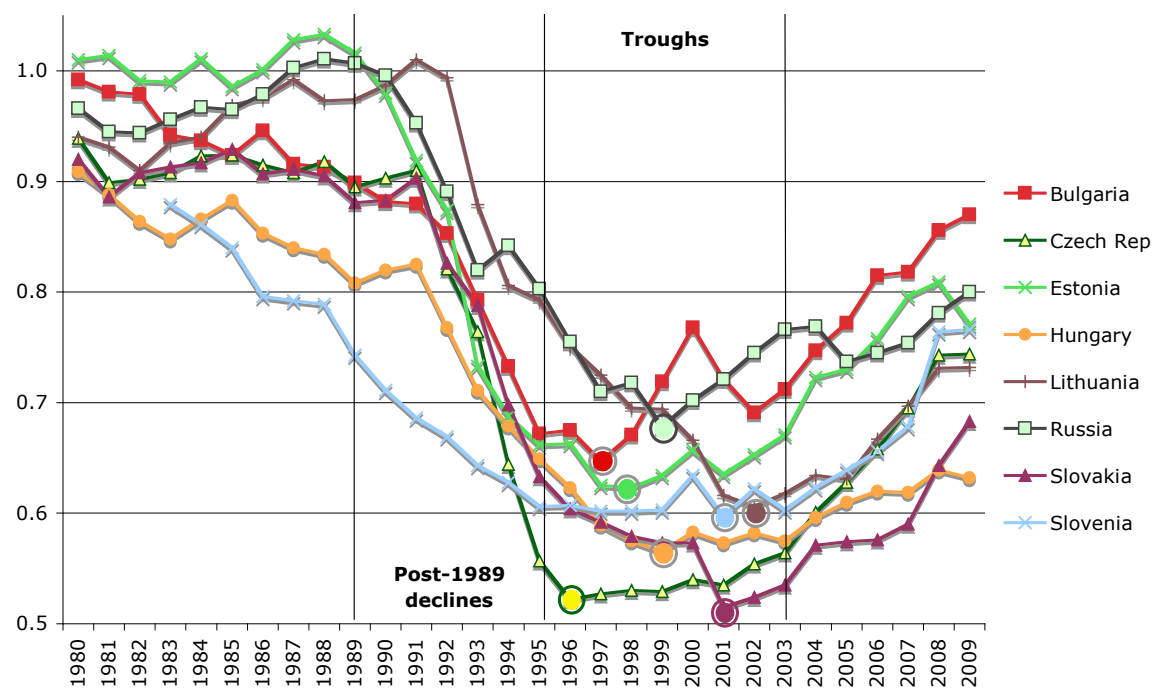

Figure 2d: Summary of changes in TFR1 in the 4 years before and 4 years after the TFR1 minima: Eastern European countries

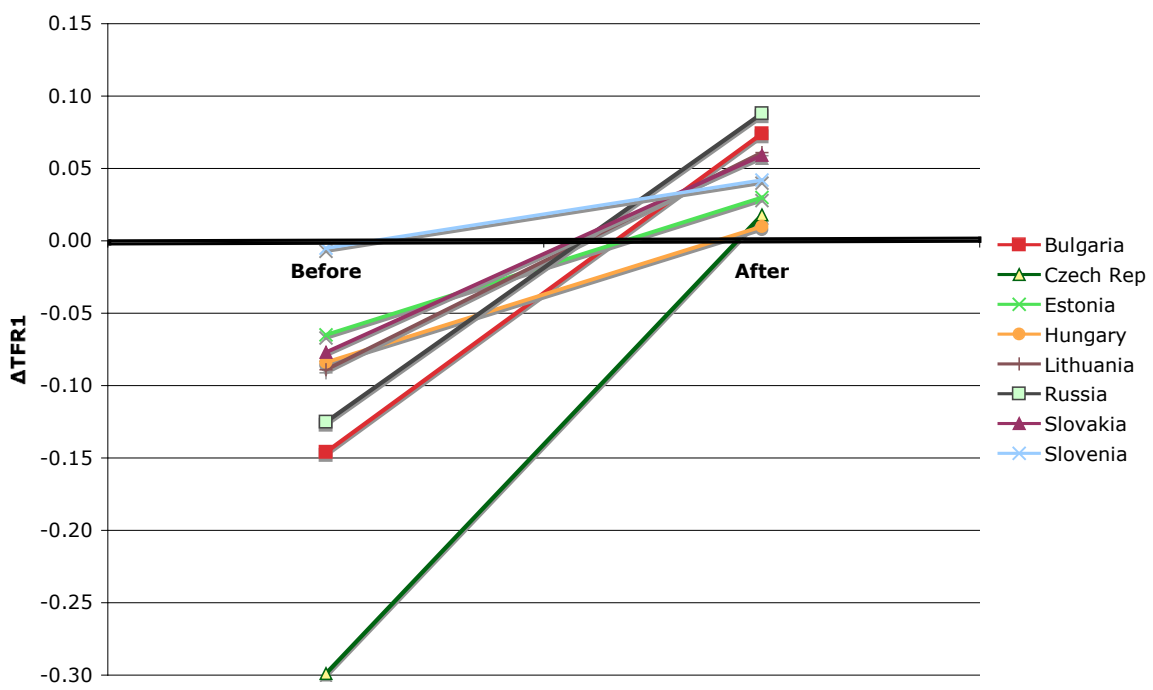




\section{Analyses}

\subsection{Overview of TFR1 trends}

The contrasting trends in TFR1 of Eastern and Western Europe since 1980 are highlighted in Figure 2. Figures 2a and 2c cover the period 1980-2011, whilst Figures $2 \mathrm{~b}$ and $2 \mathrm{~d}$ present summary graphs of the changes that occurred in the four years immediately before and after the most recent TFR1 trough. Note that the slopes of the lines on those graphs (and similar ones presenting other indicators later) are the double differentials of the rate of change between the two periods: where the slope is upwards there is an acceleration in a (positive) rate of change; a horizontal line indicates the rate of change is stable; a downward slope indicates a slowing.

For most Western European countries the fluctuations in TFR1 have been muted compared to those seen in Eastern Europe. After the troughs of 1995-2002 some countries have seen sustained and ongoing rises (Sweden, Norway, Finland). The rises were smaller in Switzerland and Austria, and in Portugal and the Netherlands they lasted only five years before there were renewed declines or fluctuations.

In Eastern Europe before the late 1980s there was a high TFR1 rate associated with low levels of childlessness and no postponement deflating the rate. In some countries trends to younger childbearing pushed the TFR1 above 1 (Estonia, Lithuania, and Russia). For some countries the decline in TFR1 started in the 1980s (Slovenia, Hungary, and Bulgaria); for others the decline was closely associated with the fall of communism in 1989. During the 1990s the declines were precipitous across the region.

For some countries there was a distinct, single trough (e.g., Sweden and Slovakia), whilst for others the TFR1 hovered around the base level for several years before rising again, sometimes with several reversals of tentative rises (e.g., Norway, Switzerland, Austria, Bulgaria, Estonia, Slovenia, Hungary). In comparing the indicators for before and after the trough we always used the specific year of the minimum TFR1 (Y0), even if the actual trough period was rather 'fuzzy'.

Comparing Figures $2 \mathrm{~b}$ and $2 \mathrm{~d}$, we see that the declines in the years immediately before the trough were generally much larger in Eastern Europe than Western Europe. However, the increases were comparable (Table 2). There is no clear division in the magnitude of the rebound comparing the countries of Eastern and Western Europe: higher and lower levels are seen in both parts of the continent. 
Table 2: Countries ordered by size of their TFR1 increase in the 4 years after the trough: Western European countries are in bold

\begin{tabular}{lc}
\hline & $\Delta$ TFR1 Y0 to Y+4 \\
\hline Sweden & 0.133 \\
Netherlands & 0.103 \\
Norway & 0.090 \\
Russia & 0.088 \\
Portugal & 0.076 \\
Bulgaria & 0.074 \\
Lithuania & 0.061 \\
Slovakia & 0.059 \\
Slovenia & 0.042 \\
Switzerland & 0.038 \\
Estonia & 0.030 \\
Finland & 0.021 \\
Czech Rep & 0.018 \\
Austria & 0.017 \\
Hungary & 0.010 \\
\hline
\end{tabular}

\subsection{Changes in height and width of the fertility curve}

A rise in TFR1 comes, by definition, from an increase in the area under the ASFR1 curve. This occurs from either an increase in the height of the curve and/or an increase in its width. The height of the curve is the modal age-specific fertility rate (Peak ASFR1). A measure of the width of the curve is the standard deviation of mean age at first birth (Std dev MAB1). We now look at whether the transition from decline to rise in TFR1s came from a change in Peak ASFR1 or a change in Std dev MAB1.

Figure 3 shows the trends in Peak ASFR1: the contrast between Eastern and Western Europe is marked, particularly for the period before Y0. Across Eastern Europe the intensity of entering into motherhood fell sharply; peak age-specific rates fell dramatically (Figures 3c and 3d). Only in Slovenia was this pattern more muted.

So we see that the sharp decline in TFR1s was caused by declines in peak rates: but did the subsequent rise in fertility rates stem from a rise in peak rates? This is shown not to be the case for the majority of countries (Figures $3 \mathrm{~b}$ and $3 \mathrm{~d}$ ). For five countries a rise in peak rates did contribute to an increase in the area under the curve (Sweden, Netherlands, Norway, Portugal, and Slovenia). However, in all other cases peak rates remained static or continued to decline. 
Figure 3a: Trends in peak age-specific fertility rates (modal rates): Western European countries

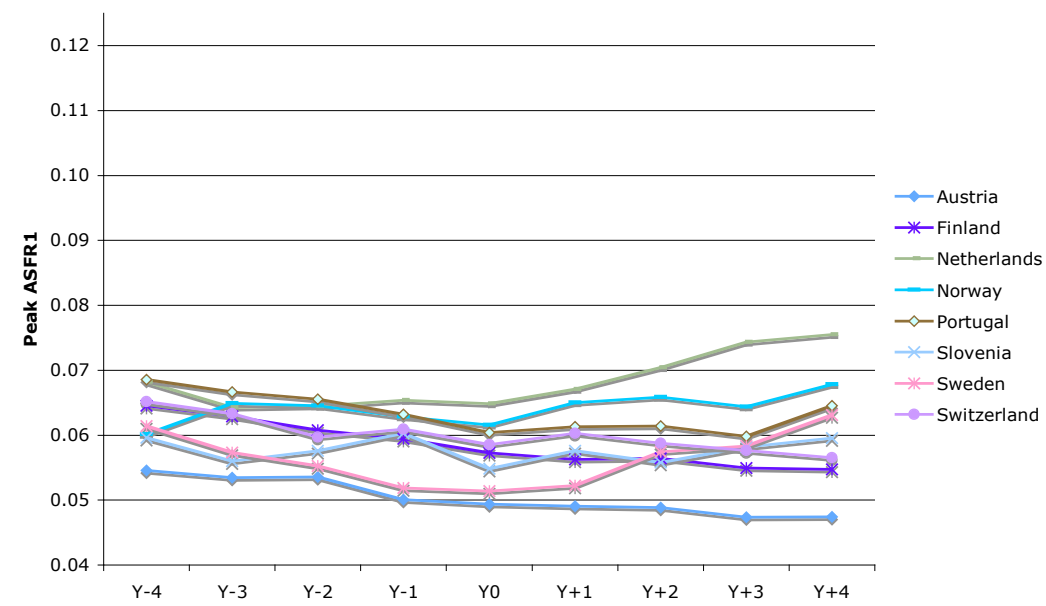

YO is year of minimum TFR1 (specific to each country)

Figure 3b: Summary of changes in peak ASFR1 in the 4 years before and 4 years after the TFR1 minima: Western European countries

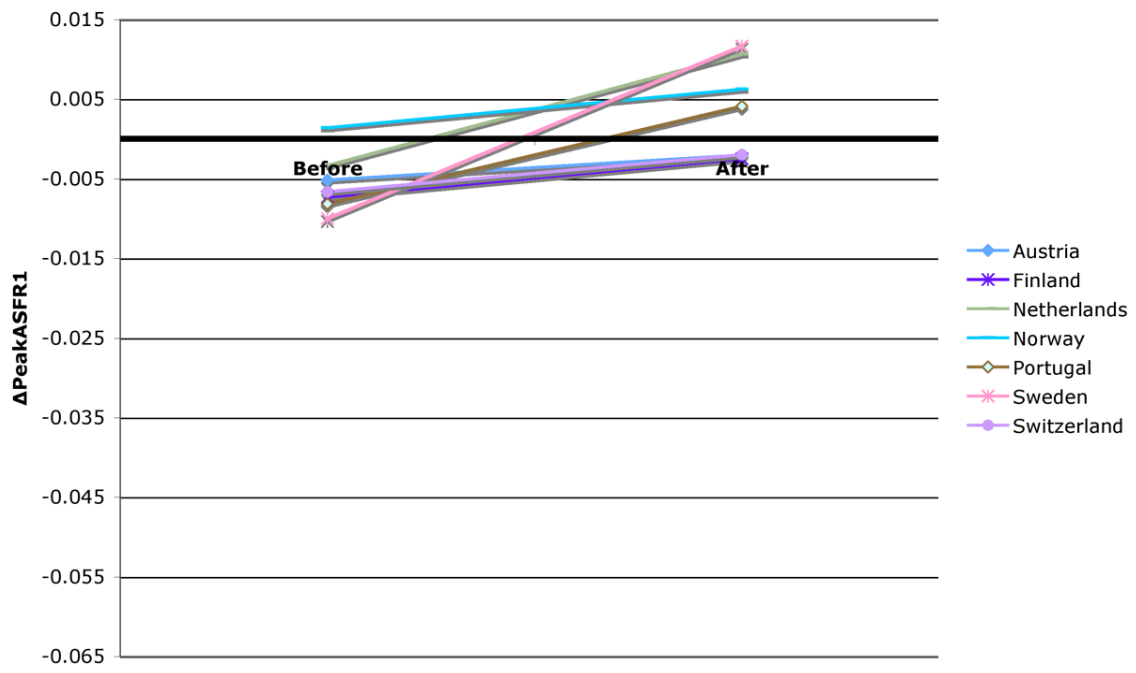


Figure 3c: Trends in peak age-specific fertility rates (modal rates): Eastern European countries

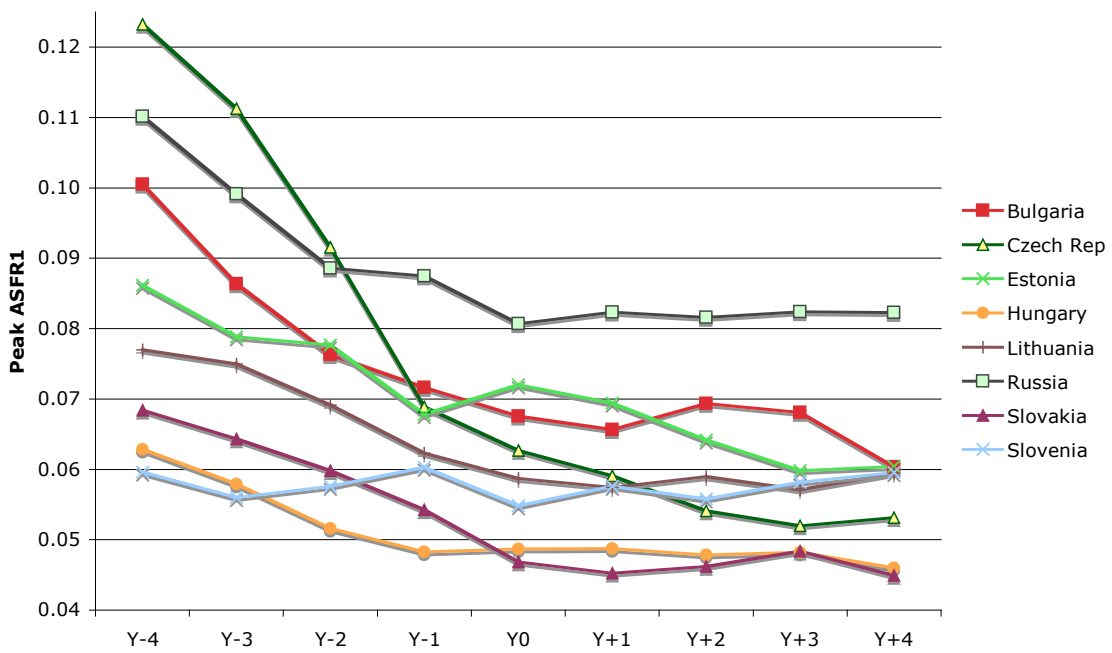

Figure 3d: Summary of changes in peak ASFR1 in the 4 years before and 4 years after the TFR1 minima: Eastern European countries

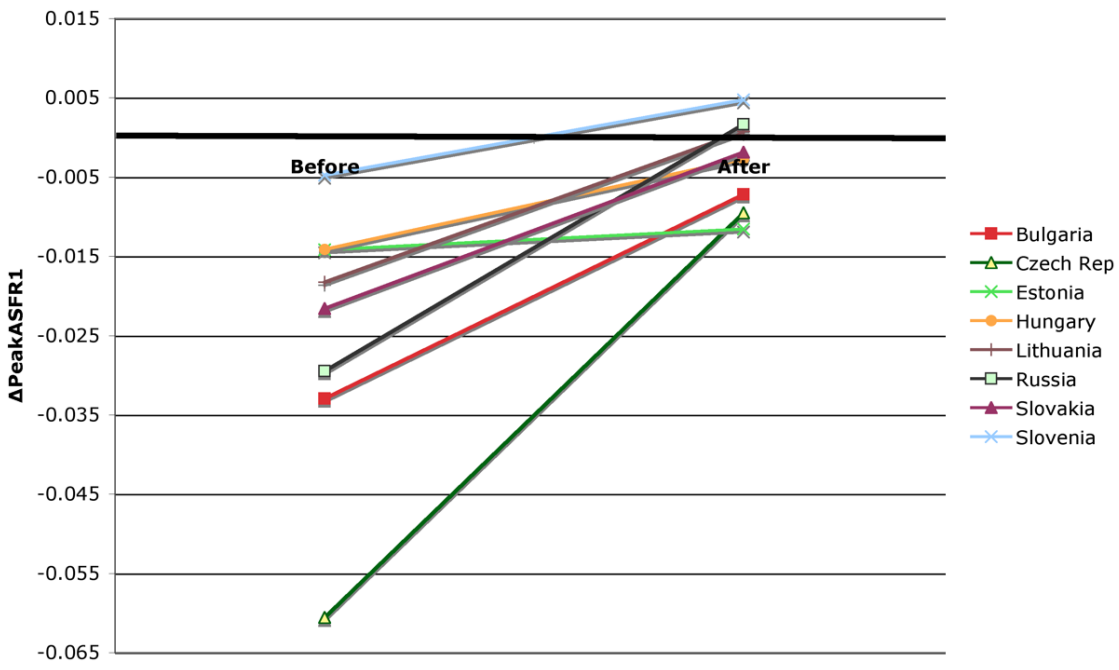


Figure 4a: Trends in standard deviation of mean age at first birth: Western European countries

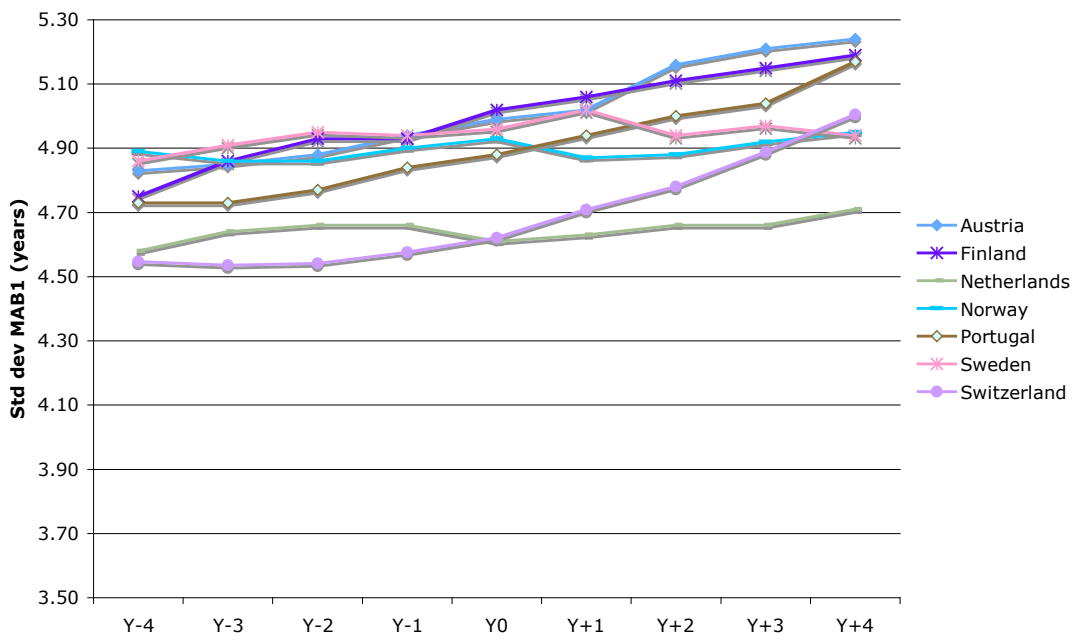

Figure 4b: Summary of changes in the standard deviation of MAB1 in the 4 years before and 4 years after the TFR1 minima: Western European countries

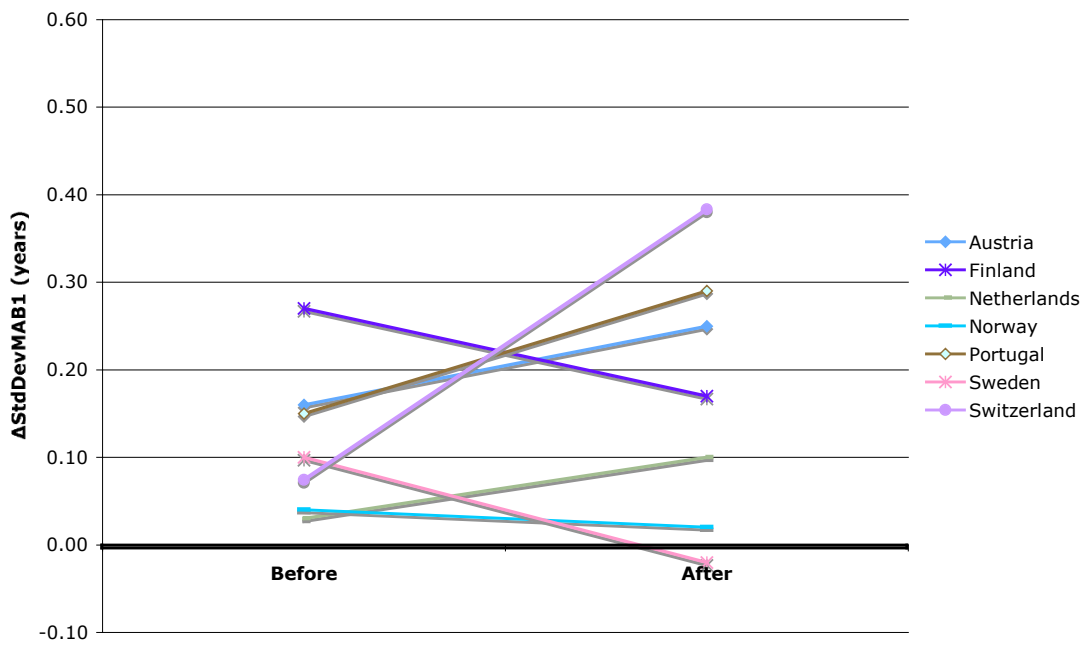


Figure 4c: Trends in standard deviation of mean age at first birth: Eastern European countries

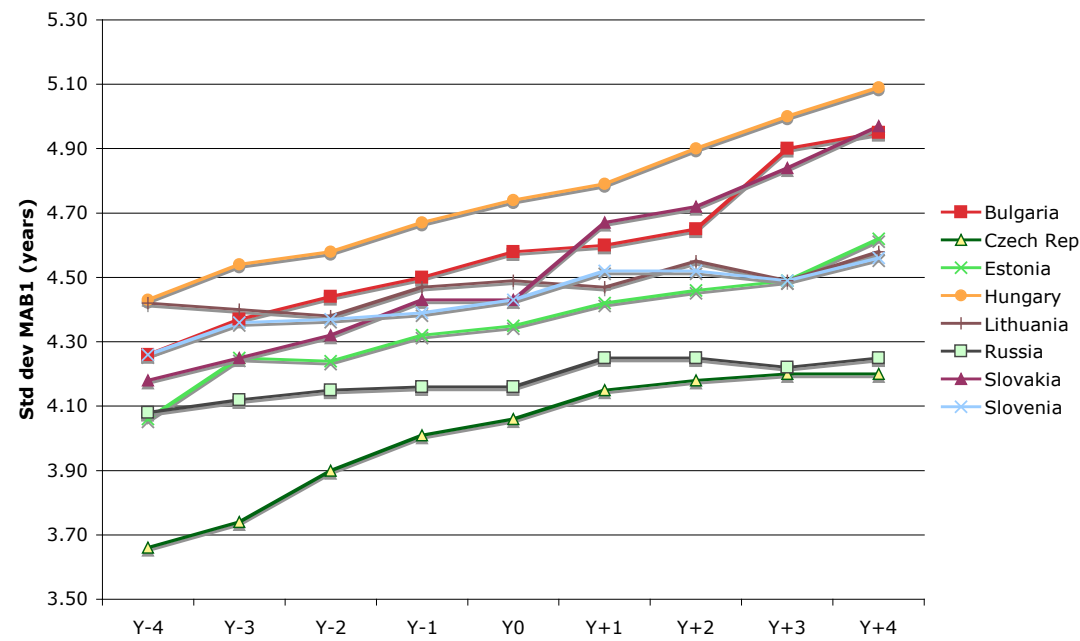

Figure 4d: Summary of changes in the standard deviation of MAB1 in the 4 years before and 4 years after the TFR1 minima: Eastern European countries

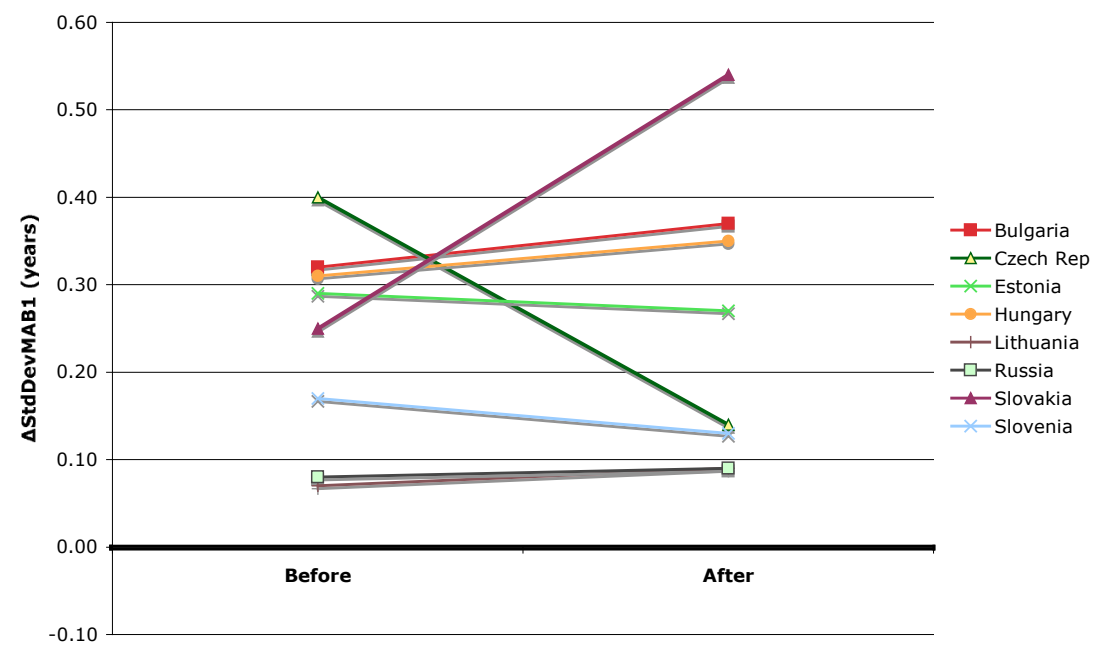


If the increase in TFR1 did not come from an increase in the height of the curve, then it must have come from an increase in the width (Figure 4). We see that this had already been rising across all countries in the years before the trough, and this trend continued (Sweden being the only exception). Most countries saw an acceleration in the increase (the slope of the summary lines in Figures $4 \mathrm{~b}$ and $4 \mathrm{~d}$ is upward, except for Finland, Norway, the Czech Republic, Slovenia, and Estonia). It should be noted that the standard deviation in MAB1 for the Western European countries was significantly higher than across Eastern Europe at the start of the period, and although the increase was strong in many Eastern European countries, only Hungary, Bulgaria, and Slovakia had reached Western European levels by four years after the trough. Russia and the Czech Republic in particular were lagging in their speed of adaptation to western norms.

These observations of the trends in height and width of the fertility curve through the TFR1 trough do not tie in well with either of Bongaarts and Sobotka's proposed models (2012). If the dip in fertility followed their 'period' model, then peak rates would decline before the trough and rise afterwards; meanwhile the width of the curve would remain constant. This is true for Sweden, one of the main four countries they studied; however, from our analysis of 14 other countries, this model is invalid. Their alternative 'cohort-driven' model shows peak rates remaining constant, but the width declining before the trough and rising afterwards. This explanation also does not 'work' for the trends observed in our data set. We see that peak rates declined significantly in the years before the trough and then stabilised. The width of the fertility curve had already been rising across all the countries in the years preceding the trough; this increase in many cases accelerated after the trough. A hybrid explanation is feasible: that the pre-trough declines were 'period-driven' (especially in Eastern Europe), whilst the post-trough rises were 'cohort-driven'.

So what did cause the area under the curve to increase after its minimum? An explanation that covers all countries is that it was a combination of two factors that caused the transition from decline to rise. The width of the curve had been rising for some time; when the fall in peak rates slowed, stopped, or sometimes reversed, this ongoing increase in the width could then more than compensate for any further reductions in the decline in peak rates.

\subsection{Source of change in the width of the fertility curve}

We now look at how the width evolved. Was it because of an increase in both the premodal and post-modal halves of the curve; or just an increase in late fertility, together 
with a stabilisation of early fertility rates, as Frejka (2012) and Goldstein, Sobotka, and Jasilioniene (2009) proposed?

We determined the modal age at first birth in the year of the TFR1 minimum; this was country-specific (unlike in all previous studies). Keeping that age fixed (even if the modal age changed over time), we then looked at the 'Early' fertility rates: the sum of the age-specific rates for all ages up to, but not including, the age-specific fertility rate of the mode (Figure 5). In a similar manner, the Late FR1 was calculated - the sum of the post-modal age-specific rates (Figure 6).

What we see in Figure 5 is that, before the TFR1 trough, early fertility was declining in all the countries; however, the rate of decline slowed everywhere in the years immediately after the trough, and in a few countries it started to slightly increase again (the Netherlands, Sweden, and Norway). This agrees to a certain extent with Frejka's model. He proposed that, in the initial period of fertility increase (Phase 2), there would be on-going postponement of young women, initially at the same rate as before, but then at a slowing rate as Phase 3 is approached, at which point young fertility stabilises. We would put the transition from decline to rise in TFR1 a little later in the Phase1-3 sequence: at the point when the decline in Early FR1 slows.

The trends for late fertility are as described by Frejka (2012). In the years immediately preceding the trough, late fertility had already started rising almost everywhere: only in the Czech Republic, Bulgaria, and (marginally) in Russia and Sweden was there a decline in the four years before the trough. After the trough the increase in late fertility accelerated (Figures 6b and 6d). In Frejka's description there is a change from stability to growth in late fertility; we show that there was a transition from slow to faster increase.

To conclude, we have shown that the increase in width of the fertility curve stems from an increase in the post-modal section of the curve, linked with a stabilisation in the pre-modal part. Expressed another way, the recuperation of older women exceeded any on-going postponement of younger women; this confirms the explanations of Frejka (2012), McDonald and Kippen (2011) and Goldstein, Sobotka and Jasilioniene (2009). 


\section{Figure 5a: Trends in Early FR1: Western European countries}

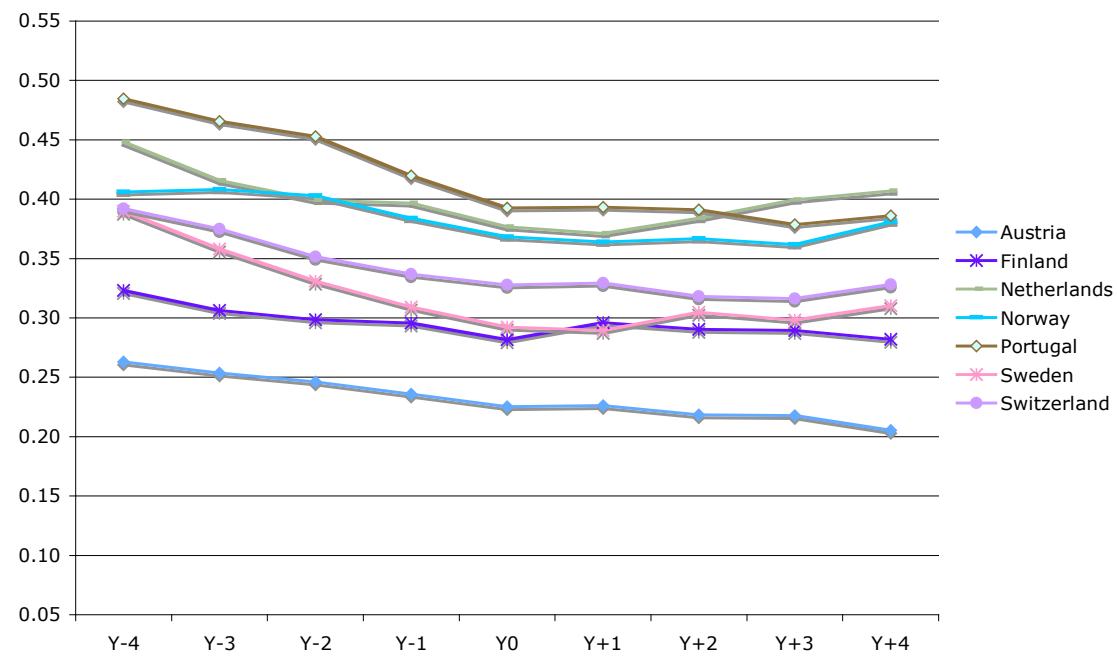

Early TFR1 is the sum of the pre-mode age-specific fertility rates (birth order 1). The modal age applied is country specific and is that in the year of the TFR1 trough.

Figure 5b: Summary of changes in Early FR1 in the 4 years before and 4 years after the TFR1 minima: Western European countries

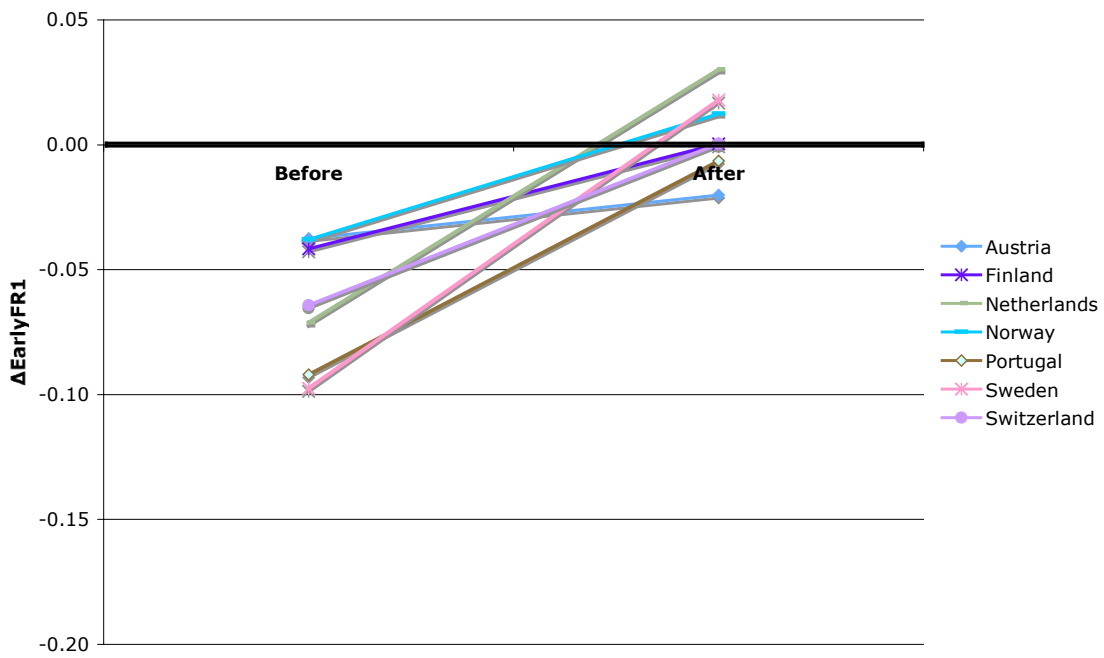


Figure 5c: Trends in Early FR1: Eastern European countries

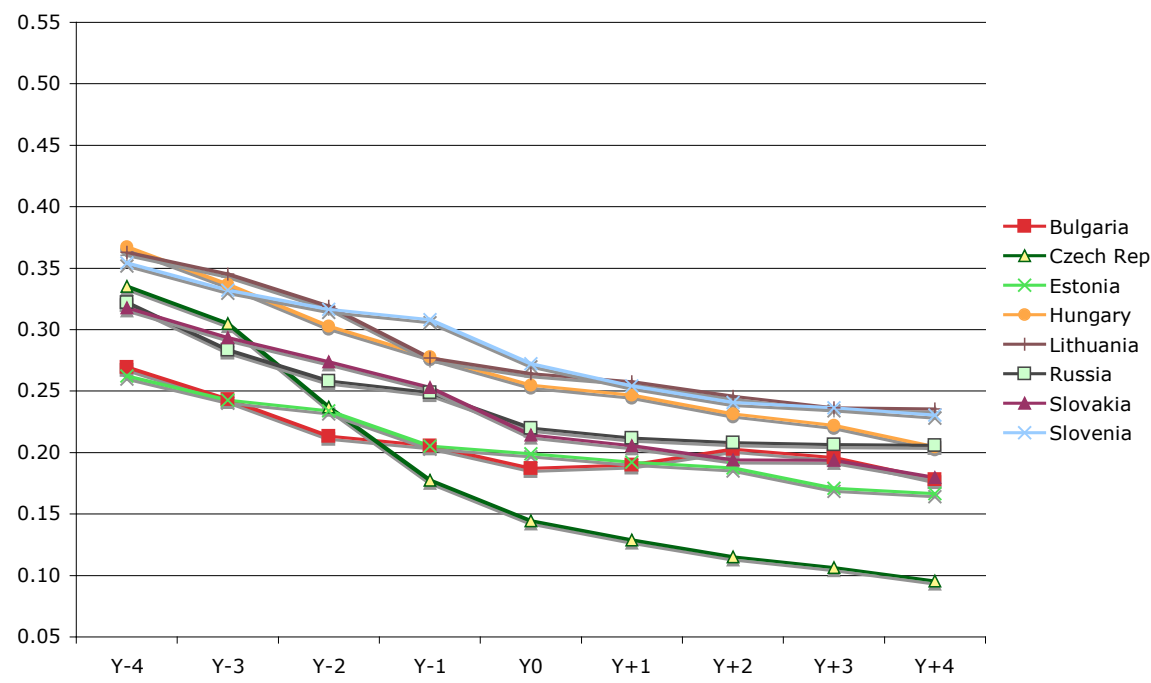

Figure 5d: Summary of changes in Early FR1 in the 4 years before and 4 years after the TFR1 minima: Eastern European countries

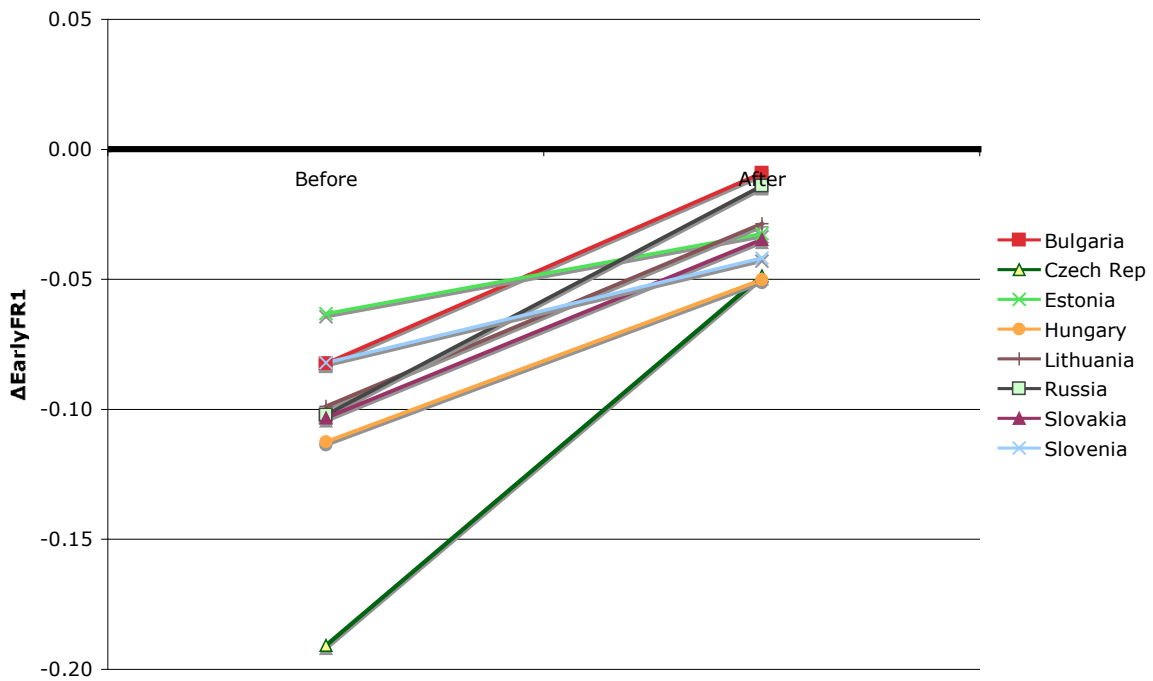




\section{Figure 6a: Trends in Late FR1: Western European countries}

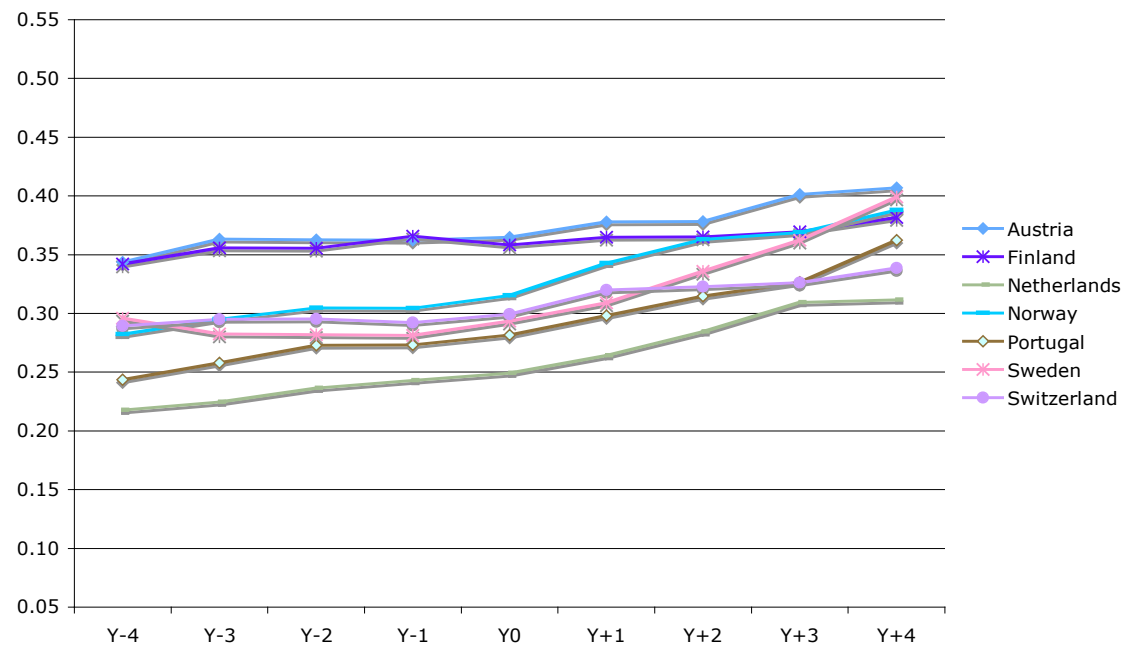

Late FR1 is the sum of the post-mode age-specific fertility rates (birth order 1). The modal age applied is country specific and is that in the year of the TFR1 trough.

Figure 6b: Summary of changes in Late FR1 in the 4 years before and 4 years after the TFR1 minima: Western European countries

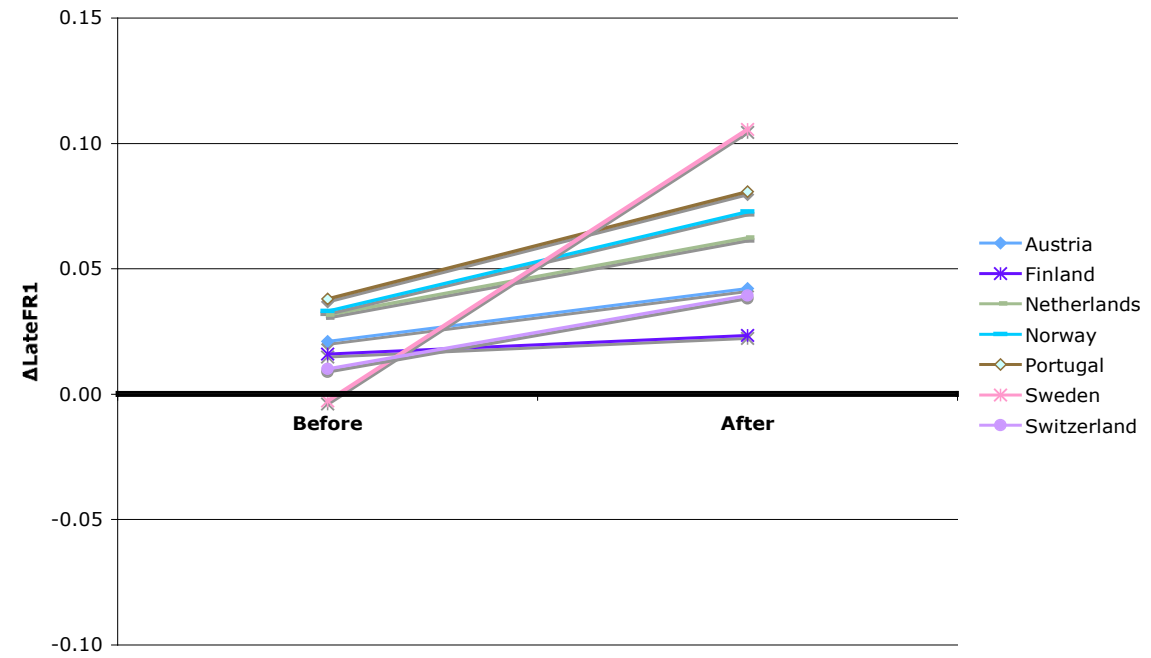


Figure 6c: Trends in Late FR1: Eastern European countries

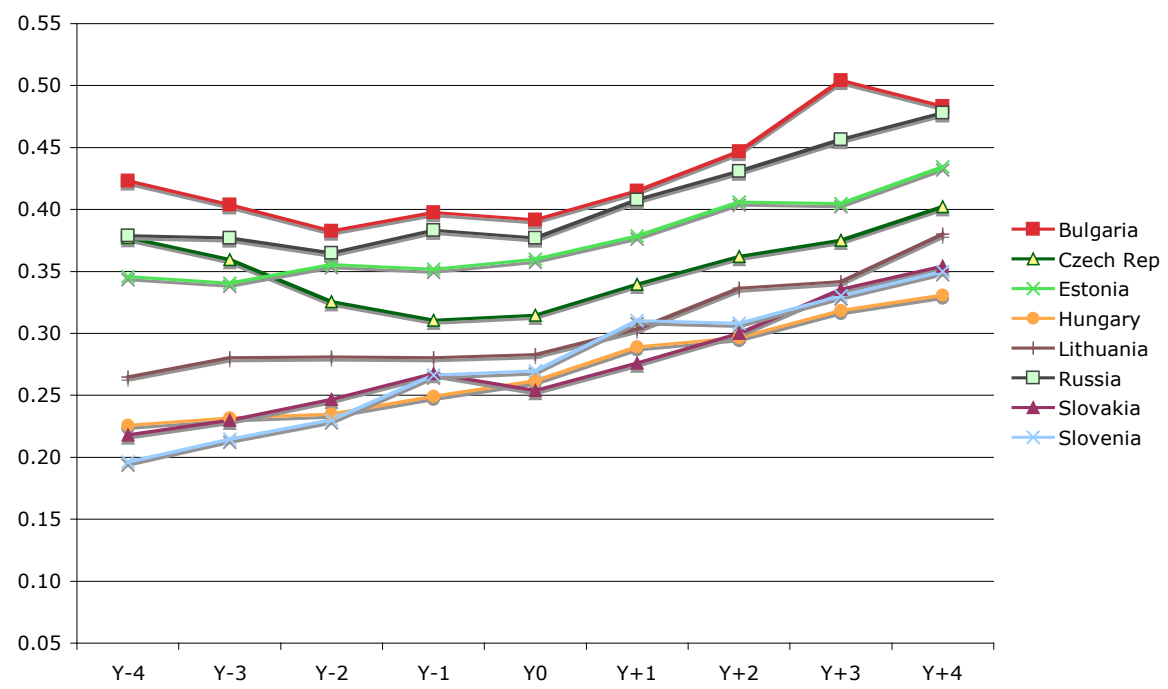

Figure 6d: Summary of changes in Late FR1 in the 4 years before and 4 years after the TFR1 minima: Eastern European countries

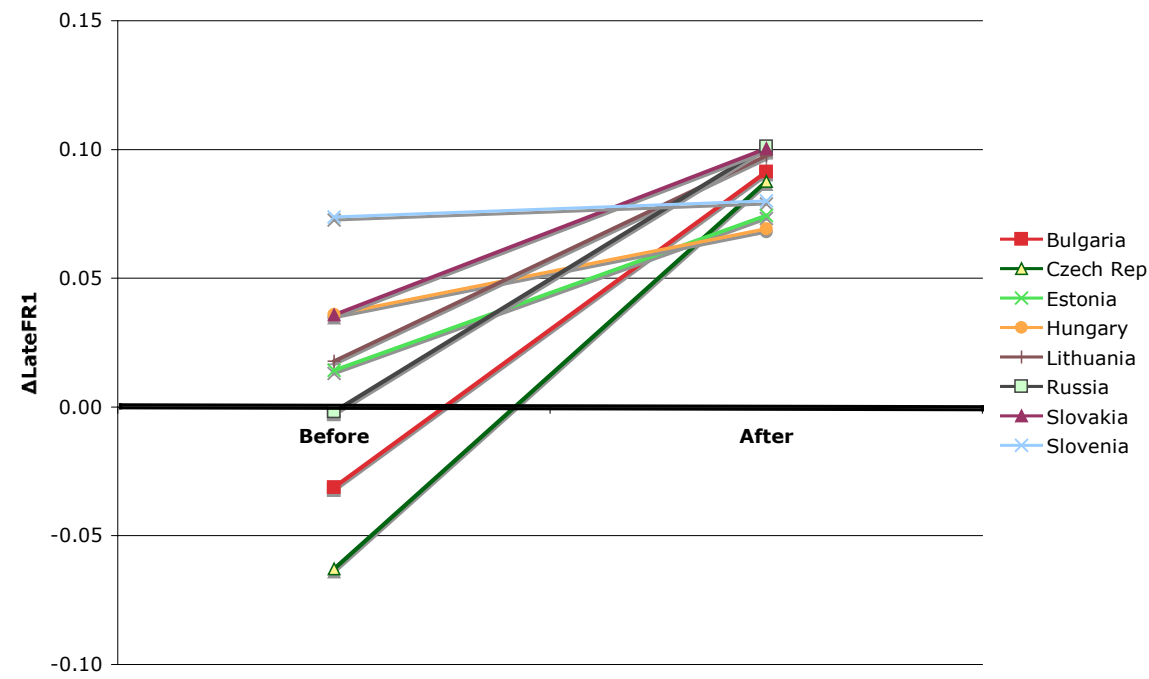


Figure 7a: Trends in MAB1: Western European countries

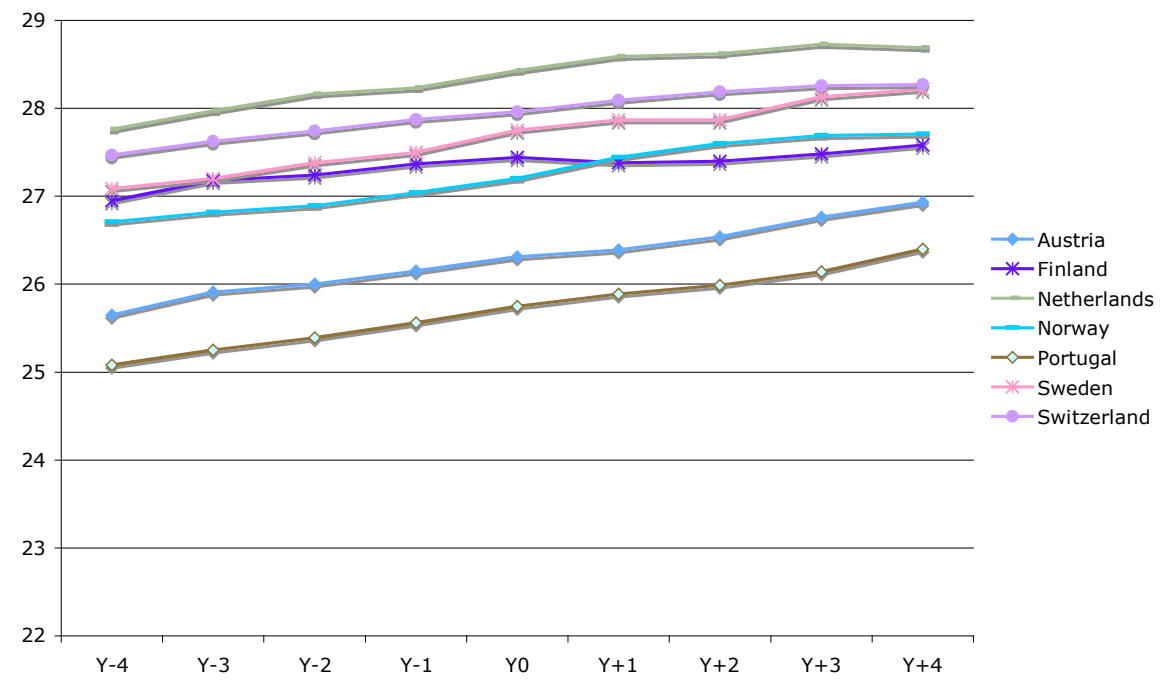

Figure 7b: Summary of changes in MAB1 in the 4 years before and 4 years after the TFR1 minima: Western European countries

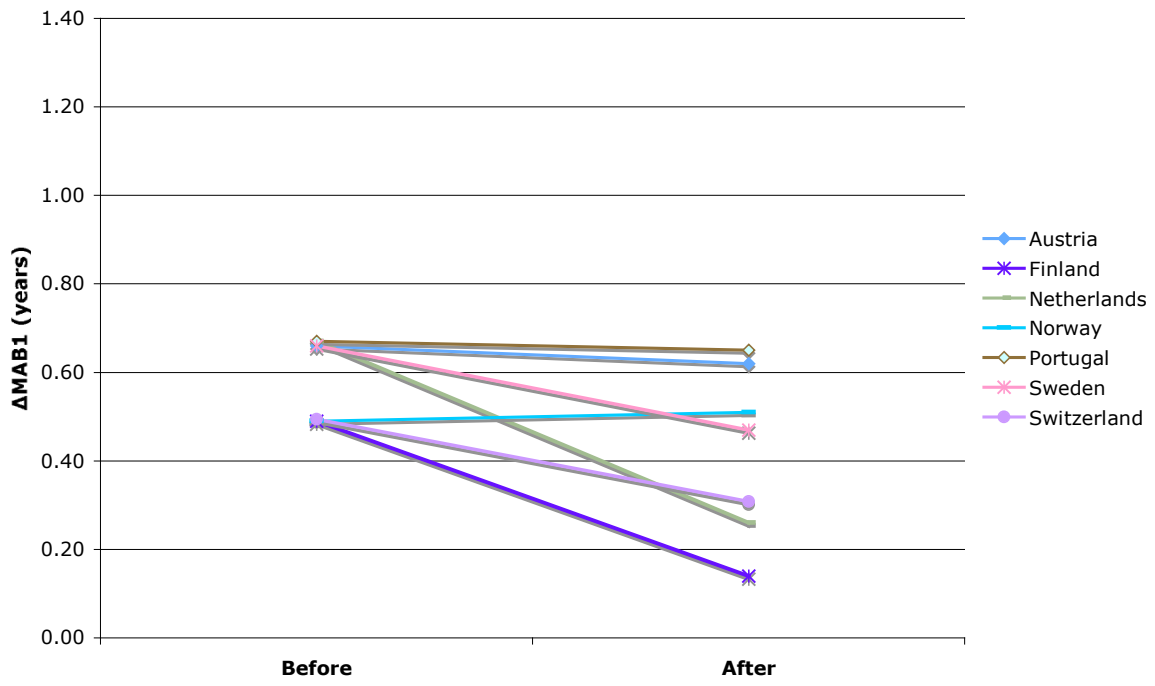


Figure 7c: Trends in MAB1: Eastern European countries

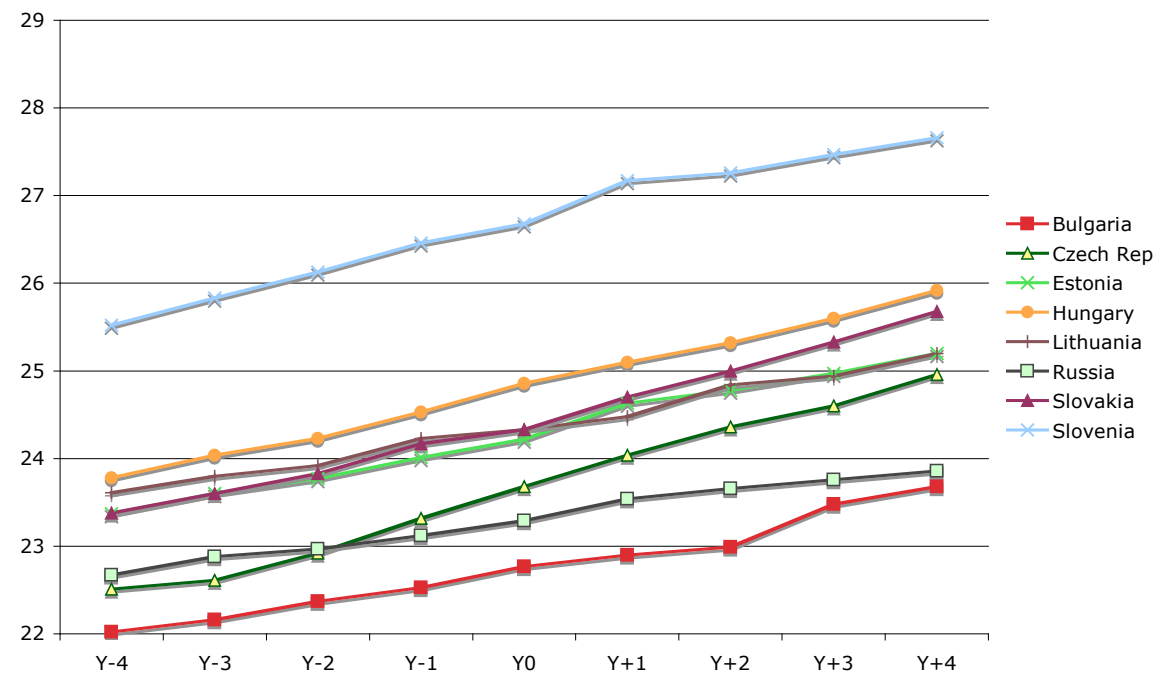

Figure 7d: Summary of changes in MAB1 in the 4 years before and 4 years after the TFR1 minima: Eastern European countries

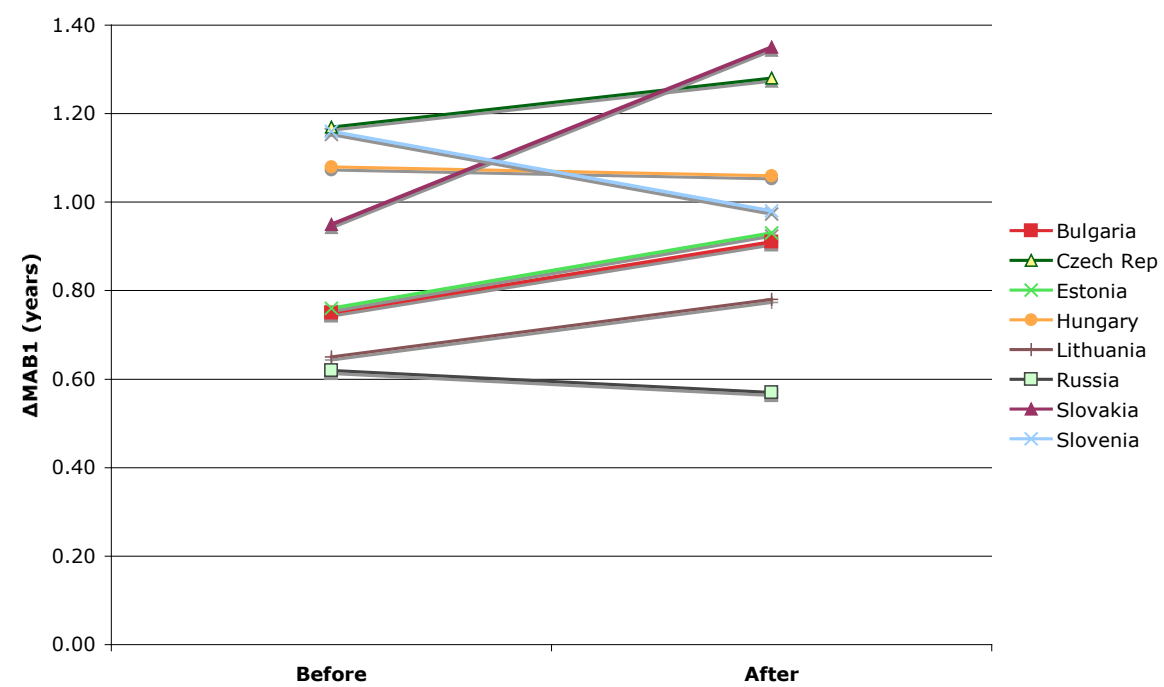




\subsection{Changes in mean age at first birth}

A rise in period fertility rates had been predicted by demographers before the rates actually started rising, because they had been aware that period rates had been deflated for some time with the ongoing rise in age of entry into motherhood (MAB1) (Bongaarts and Feeney 1998). Therefore, when the rates started rising it was assumed $a$ priori that the cause was a slowing in postponement rates, and hence tempo distortions were declining (Bongaarts and Sobotka 2012). In this section we examine whether this happened.

Bongaarts and Sobotka (2012) define postponement as an increase in mean age at first birth. A declining postponement rate would be a decline in the rate of increase in MAB1. Postponement could still be happening, but at a slower rate. To examine whether this actually happened we plotted the trends in MAB1 plus summary graphs of postponement rates (Figure 7). We find the picture is mixed. Both the absolute mean age at first birth and the change over the transition period were different in Western Europe compared to Eastern Europe. There was a significant slowing of postponement in Sweden, Switzerland, the Netherlands, and Finland. However, postponement rates remained essentially stable in Portugal, Austria, Norway, and also Hungary. There were very slight declines in the postponement rates in Russia and Slovenia, but across the other five countries of Eastern Europe there was an acceleration in the increase in mean age at first birth.

The reason for this apparent anomaly is that late fertility was rising faster than early fertility was falling, which pushed up the MAB1 at an accelerating rate, especially in Eastern Europe. This is the explanation elaborated by Goldstein, Sobotka, and Jasilioniene (2009:58), who present a stylised model of the changing pace of postponement in their Figure S3. This shows a slowing and then renewed (temporary) quickening over the transition period through the TFR trough.

Declining postponement is, indeed, part of the story of how fertility rates came to rise: but it was the contribution of declining young (pre-modal age) postponement that was the factor and not declining postponement per se. The strong increase in late fertility pushed up the MAB1 in many countries, especially in Eastern Europe, so that the trend in the mean age at first birth did not behave as would be expected if the width of the curve had remained constant.

\subsection{Comparison of cohort and period trends}

The question of whether the rises in TFR1 were caused solely by changed timing, or whether (or not) there were also increases in cohort fertility, is important. Myrskylä, 
Goldstein, and Cheng (2013), used a method of projecting cohort fertility which we term 'age-specific trend with limited extrapolation' (ASTLE). For cohorts who have not completed their reproductive period, the most recent 5 years of age-specific trends are calculated and extrapolated for a further 5 years and then frozen. We applied the ASTLE method using latest available fertility data (mostly up to 2010/2011) to calculate cohort fertility for birth order 1 . As it is now at least seven years since the trough, we can reasonably assess the trends for the cohorts that were at their peak fertility when passing through the period trough. Figure 8 summarises the trends of the relevant cohorts showing the first birth fertility rates for the 1965-80 cohorts and summary graphs for the transition period through the trough.

The first thing to note is that, for all countries, the cohort levels are higher - often considerably - than the period rates. Whilst period TFR1 rates dipped to only just above 0.5 (Czech Republic in 1996 and Slovakia in 2001), cohort CTFR1 rates have in no instances (yet) dipped below 0.75. This has important implications for rates of lifetime childlessness. We predict that the childlessness rate of the 1965-1980 cohorts is likely to be no greater than $24 \%$ (the 1980 cohort in Hungary), and it could be less if recuperation at older ages accelerates even more. Austria, Finland, and Slovakia are likely to have childlessness rates of around $20 \%$.

As well as being higher than period rates, cohort fertility is considerably more stable than period trends (Figures $8 \mathrm{~b}$ and $8 \mathrm{~d}$ ). In some countries, the quantum was rising both before and after the trough (Lithuania, Bulgaria, and Sweden). In other countries - Switzerland, Norway, Finland, the Netherlands, and Estonia - slight declines changed to slight increases. In the majority of Eastern European countries plus Portugal, quantum declines were taking place before the trough and these continued, although at a slightly slower pace, after the period minimum. For Austria, the slight rise in cohort fertility rates before the trough turned into a decline after it.

Comparing our results with those of previous studies, we generally - though not always - see similar trends (Table 3). There are (at least) three reasons for discrepancies: first, the changes are generally small, so the definition of 'stability' and 'increase' or 'decline' is debatable; secondly, the previous studies combined all birth orders, whereas ours covers only first births; and thirdly, the analysed data sources, selections of countries, and cohort bands are diverse. Frejka (2012) generalised that most countries he had studied had declining cohort fertility, whereas Myrskylä, Goldstein, and Cheng (2013) concluded that cohort rates were generally increasing; the verdict of Bongaarts and Sobotka (2012) was 'stability'. We conclude that significant quantum trends are happening in some countries and these influenced the rate of change of period fertility through the trough. 
Burkimsher: Europe-wide fertility trends since the 1990s

\section{Figure 8a: Trends in CTFR1 1965-1980 cohorts: Western European countries}

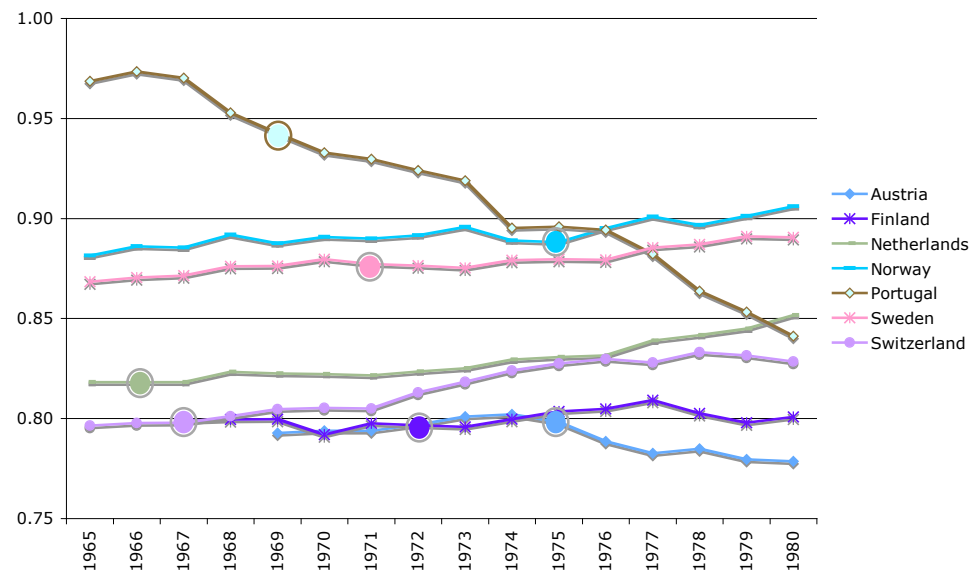

Cohort fertility rates are based on period data up to 2010/2011 and then projections using ASTLE method (see text).

Circled points are for the cohort associated with the peak ASFR1s in the year of the period trough e.g., Sweden had its TFR1

minimum in 1998. In that year the peak ASFR1 was for 27 year-olds. Their year of birth was 1971 (=1998-27).

Note that the vertical scale covers only half the vertical span of that in Figures $2 \mathrm{a}$ and $2 \mathrm{c}$.

Note that the horizontal scale covers only 16 cohorts compared to a time span of 29 years in Figures $2 \mathrm{a}$ and $2 \mathrm{c}$

\section{Figure 8b: Summary of changes in CTFR1: Western European countries}

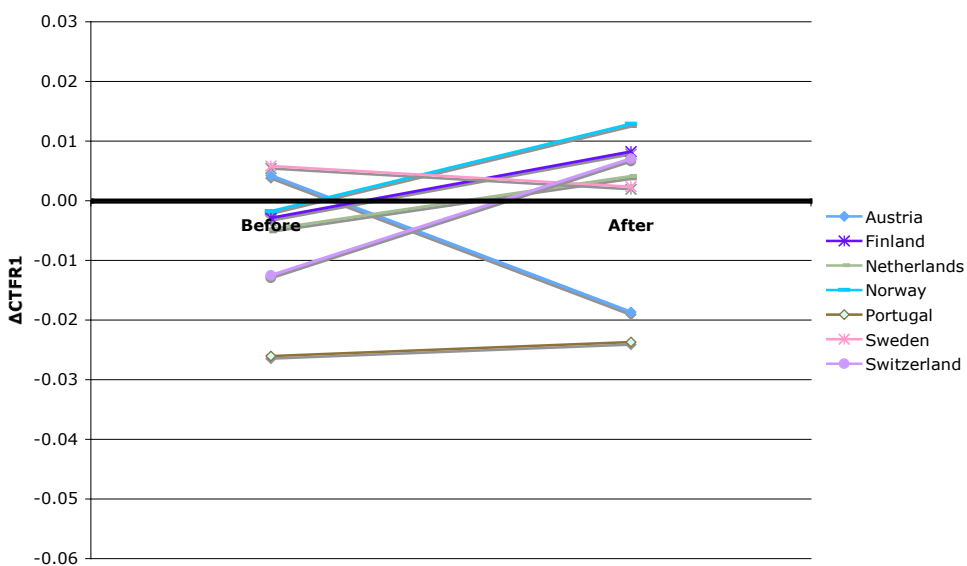

These relate to the changes in the cohorts 4 years older and younger than the cohort associated with the period trough, e.g., for Sweden the "before" data point is the change in CTFR1 between the 1967 and 1971 cohorts and the "after" data point is the change in CTFR1 between the 1971 and 1975 cohorts 
Figure 8c: Trends in CTFR1 1965-1980 cohorts: Eastern European countries

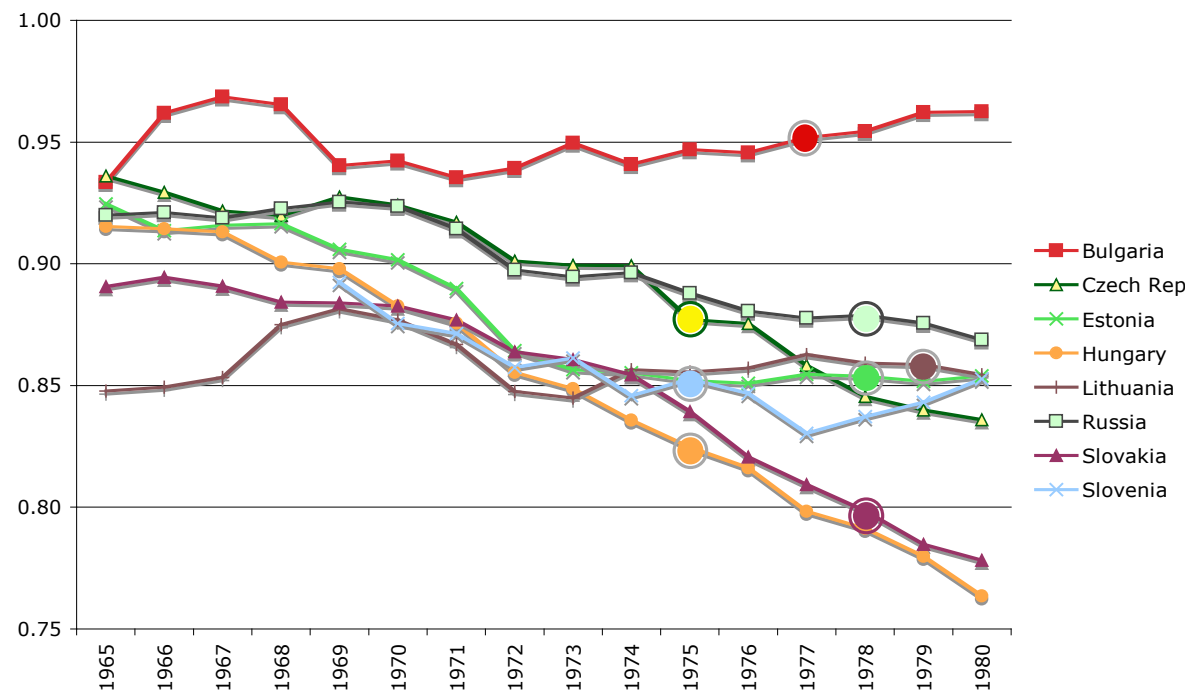

Figure 8d: Summary of changes in CTFR1: Eastern European countries

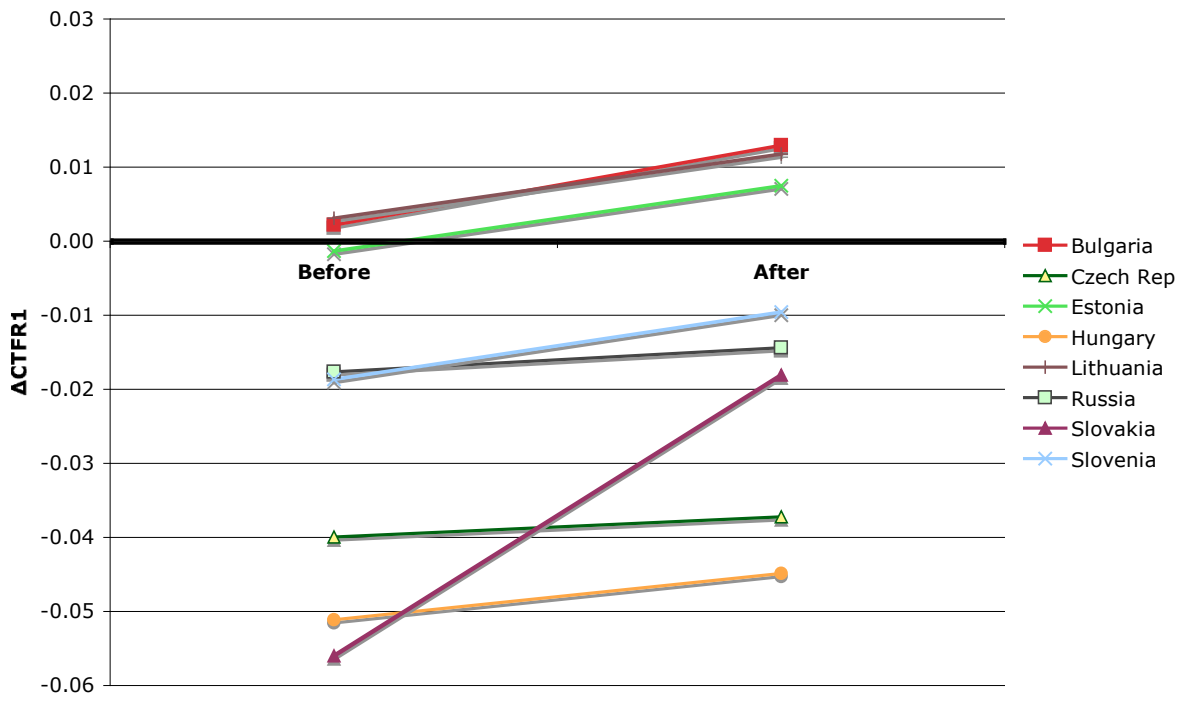


Table 3: Comparison of cohort fertility trends of different studies

\begin{tabular}{|c|c|c|c|c|}
\hline & $\begin{array}{c}\text { Current analysis, } \\
\text { birth order } 1\end{array}$ & Frejka (2012) & $\begin{array}{l}\text { Bongaarts and } \\
\text { Sobotka (2012) }\end{array}$ & $\begin{array}{l}\text { Myrskylä, Goldstein, } \\
\text { and Cheng (2013) }\end{array}$ \\
\hline Austria & - & & & - \\
\hline Bulgaria & + & & + & + \\
\hline Czech Rep & - & - & $=$ & - \\
\hline Estonia & $=$ & & $=$ & $=$ \\
\hline Finland & $=$ & & $=$ & $=$ \\
\hline Hungary & - & & & - \\
\hline Lithuania & + & & & + \\
\hline Netherlands & $=$ & - & $=$ & + \\
\hline Norway & + & - & & + \\
\hline Portugal & - & & & - \\
\hline Russia & - & - & $=$ & + \\
\hline Slovakia & - & & & - \\
\hline Slovenia & $=$ & & $=$ & $=$ \\
\hline Sweden & $=$ & & $=$ & + \\
\hline Switzerland & $=$ & - & $=$ & $=$ \\
\hline
\end{tabular}

Current analysis covers the change in the 4 post-trough cohort years

+ increase of $>0.01 ; \quad$ - decline of $>-0.01 ; \quad=$ change less than 0.01

To investigate the effects, we can compare the post-trough increases in TFR1 (Table 2) with the trends in CTFR1 (Table 3). It is not surprising that in countries with ongoing quantum falls (Hungary, Czech Republic, Austria) there were only muted period rises. Concomitantly, in countries where quantum rises are on-going (Sweden, Bulgaria, and Lithuania) the TFR1 had higher than average increases. However, there are also counter-examples: Portugal and Russia had ongoing cohort declines but significant upturns in their period rates after the trough.

One final note on cohort trends: summing age-specific rates through the reproductive life of a cohort may not always produce a correct parity distribution of those cohorts, the reason being differential immigration and emigration of women with different family sizes (Kreyenfeld et al. 2012). Therefore, the ultimate childlessness rate in a country may not turn out to be that calculated from summing ASFR1s through a cohort's reproductive life. 


\subsection{Is change in the parity composition part of the explanation?}

So far in this paper we have examined 'incidence' rates; these are pure age-specific rates, not taking into account the number of children already borne. A potentially better measure for describing fertility trends, which takes into account the distribution of childless women by age, and who are therefore 'at risk' of having a first child, is the PATFR1 (Rallu and Toulemon 1994; Sobotka 2003, 2004). To derive this summary index, a fertility table is constructed and age- and parity-specific birth probabilities are calculated; this is exactly equivalent to the life table method for mortality. The values of the PATFR1 indicator are available in the Human Fertility Database.

The trends in PATFR1 for the period 1991-2009 are shown on Figure 9. Several observations can be made from these graphs. Firstly, comparing the values for the PATFR1 with those of the TFR1 (Figures $2 \mathrm{a}$ and $2 \mathrm{c}$ ) and the projections for CTFR1 (Figures $8 \mathrm{a}$ and $8 \mathrm{c}$ ), it is clear that the PATFR1 values are higher than the TFR1 but lower than the associated CTFR1 for the period under study (note different vertical scales). The trends in the PATFR1 are in a similar direction to those seen in the TFR1, but at a more subdued level.

Figures 10a and 10b show how the PATFR1 and TFR1 diverged through the 1990s and then converged again; this was especially marked for the Eastern European countries. By 2009 four European countries had almost identical values for the two indicators: Sweden, the Netherlands, Norway, and Finland.

Another interesting observation is the timing of the troughs in the PATFR1 compared to the TFR1 minima (Table 1). In 7 of the countries ( 3 in Western Europe, 4 in Eastern Europe) the year of the trough was identical. However, in the other 8 countries the PATFR1 minimum was reached after the TFR1 trough.

What does this signify? When the PATFR1 is higher than the TFR1 it means that the probability of a woman having her first child is higher than would be expected if the parity-by-age structure were constant over time. In these cases there is an excess or 'backlog' of childless women; this is the situation when postponement has been happening (Sobotka 2004). The renewed convergence of the PATFR1 and TFR1 indicators suggests that a catching-up process is at work, although, except in the cases of Sweden, the Netherlands, Norway, and Finland, the process is still incomplete.

The rise in TFR1 was not solely attributable to the parity structure, however, at least after the PATFR1 minima had been reached. At that point, first birth probabilities for women at higher ages started to increase (as described in Sobotka 2004:49). However, for the five countries where the PATFR1 indicator has not risen significantly (the Netherlands, Austria, Portugal, Russia, and Hungary), then the probability of having a first child has changed little in the decade since 2000 . 
Figure 9a: Trends in PATFR1 1990-2011: Western European countries

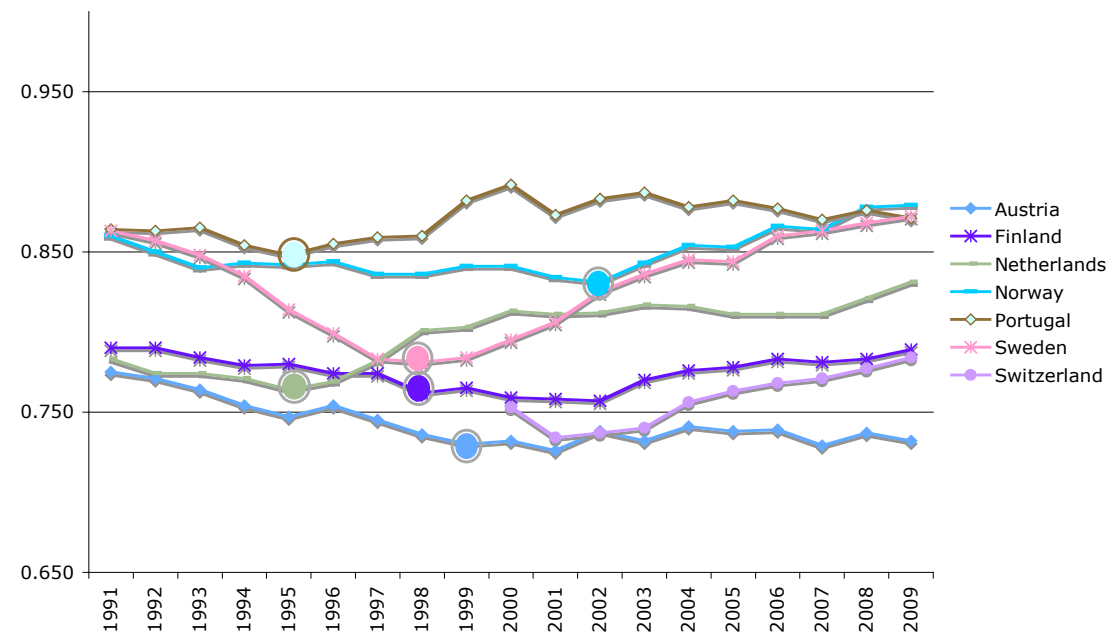

Note: circles denote year of minimum TFR1 for the countries plotted. PATFR1 data not available for Switzerland for years prior to 2000

Figure 9b: Summary of changes in PATFR1 in the 4 years before and 4 years after the TFR1 minima: Western European countries

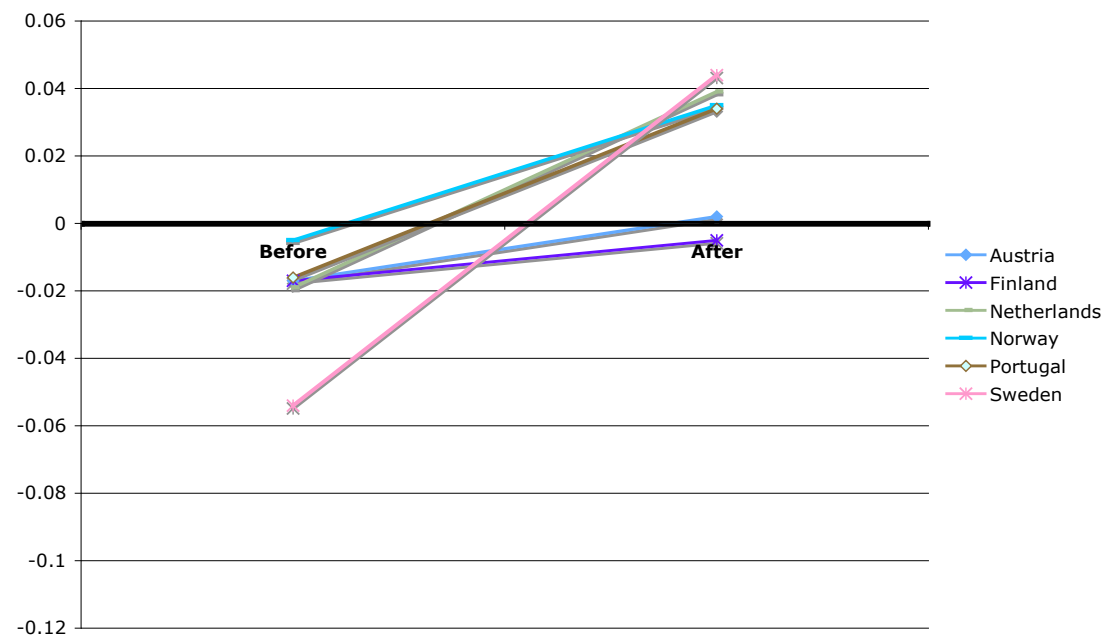


Figure 9c: Trends in PATFR1 1990-2011: Eastern European countries

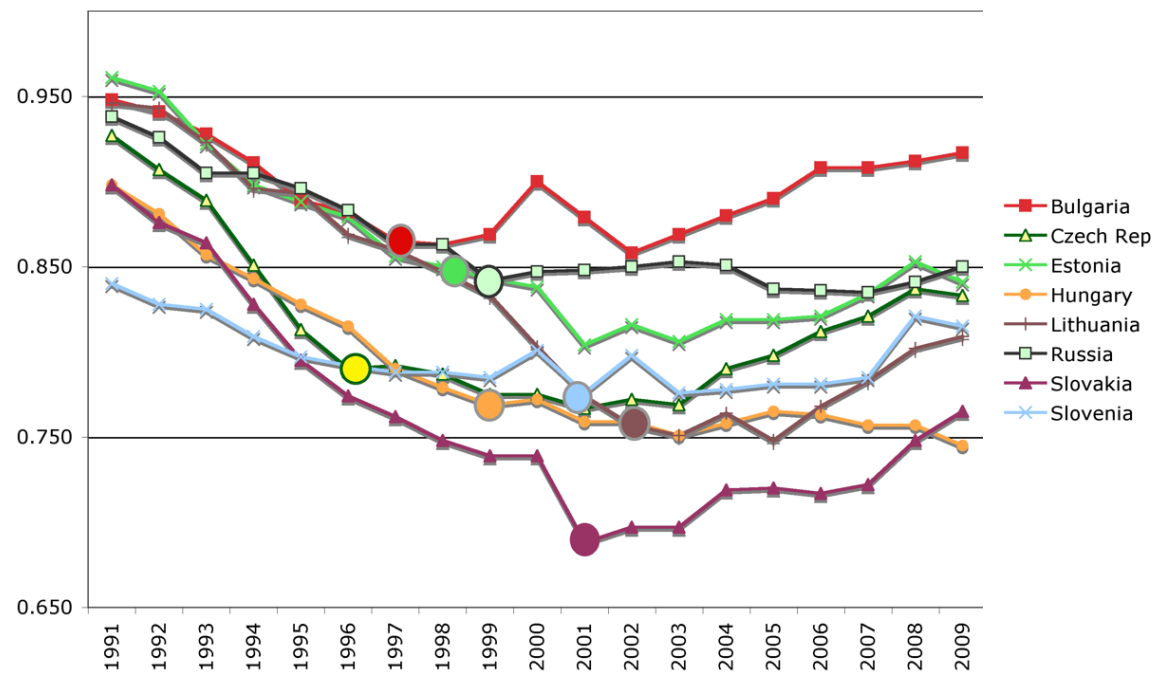

Figure 9d: Summary of changes in PATFR1 in the 4 years before and 4 years after the TFR1 minima: Eastern European countries

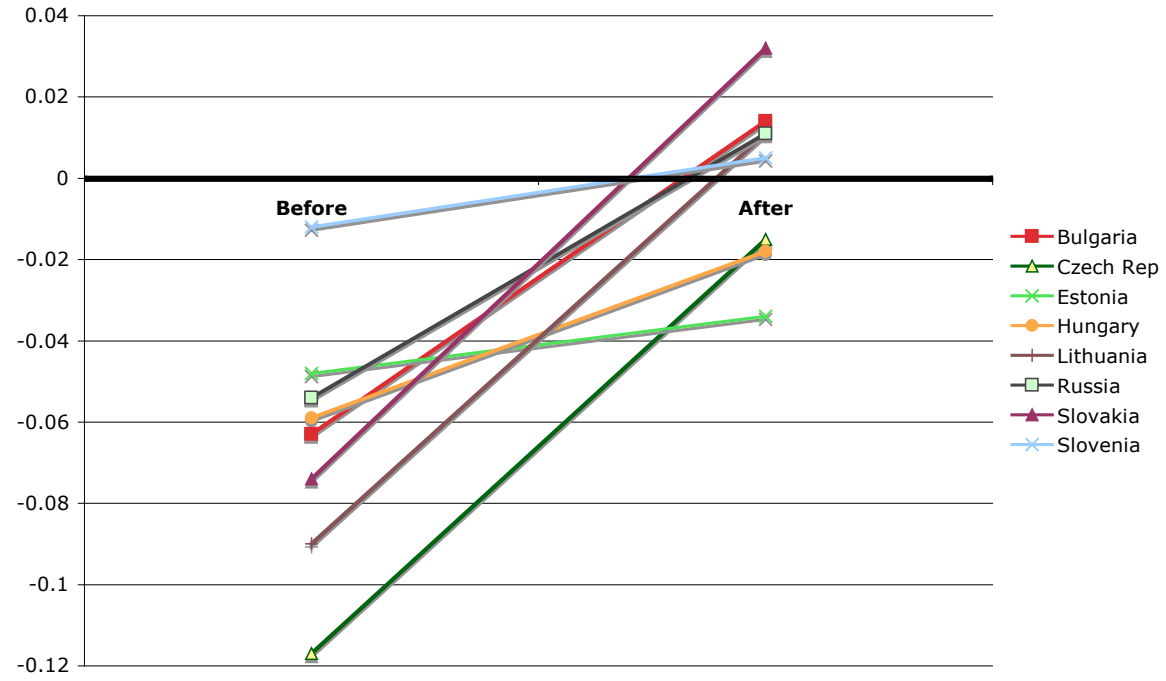


Burkimsher: Europe-wide fertility trends since the 1990s

Figure 10a: Trends in (PATFR1 - TFR1): Western European countries

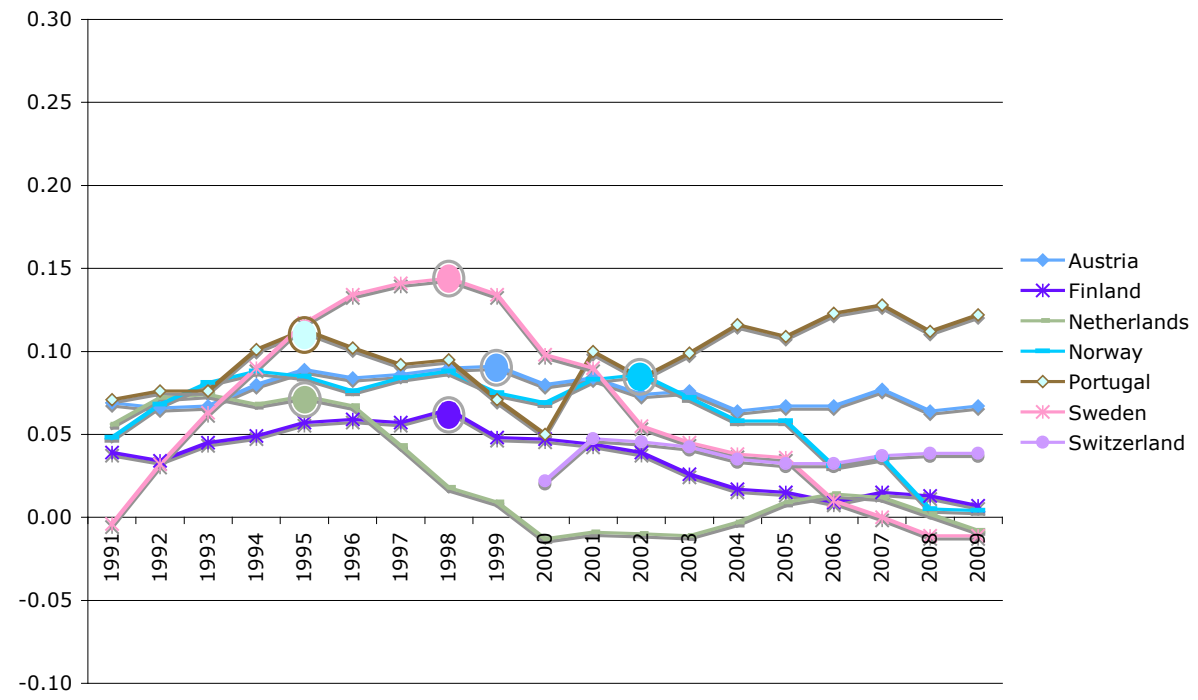

Figure 10b: Trends in (PATFR1 - TFR1): Eastern European countries

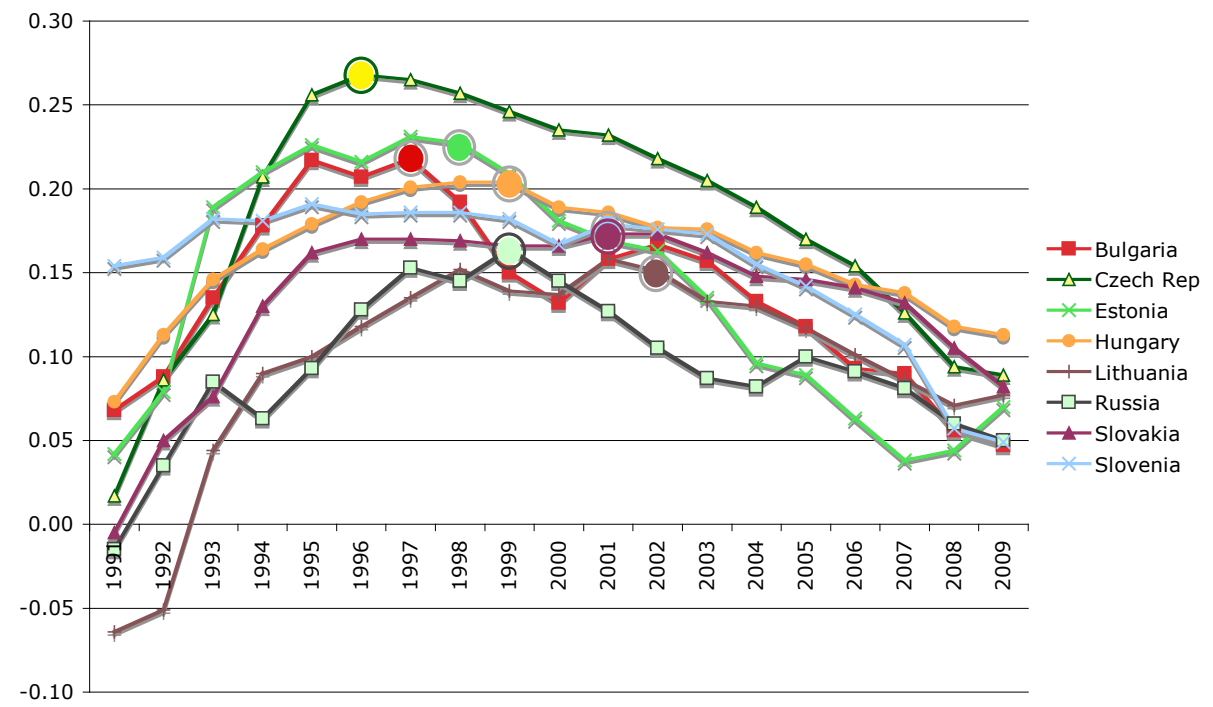


The explanation of the mismatch in timing of the troughs in PATFR1 compared to TFR 1 is related to different forces being at work. In those countries where the upturn in the TFR1 occurred first, there was initially no increase in 'propensity' to have a first child; the TFR1 started to rise solely because of the parity structure, because there was an 'excess' of childless women in the population. It was only after this demographic 'imperative' caused an increase in the 'apparent' (TFR1) birth rate that the likelihood of having a first child, as defined by the PATFR1, then started to increase. The full fertility tables show that it was older women who experienced this increased 'intensity' of entering motherhood (Sobotka 2004:48). Interestingly, in 11 of the countries studied, the trough in PATFR1 was reached in the narrow period of 2001-2003. Might specific factors have kicked in around that time across Europe to increase the probability of having a first birth?

\section{Conclusion}

This study has presented a comprehensive set of indices to explain the TFR rises. Previous results and conclusions have been investigated and, in some cases, challenged; comprehensive discussions of these are in section 4.

McDonald and Kippen (2011:4) summarised their explanation for the observed fertility trends in Australia as follows: "The TFR has risen in recent years because women at older ages have been having the births that had been delayed in the past while women at younger ages have ceased delaying their births any further than earlier cohorts did". We would almost completely concur with this statement in respect to the trends seen in the 15 European countries analysed and applied specifically to first birth rates. In all cases there was a slowing (although not always stopping) of the decline in early (pre-modal age) birth rates, together with an ongoing and often accelerating rise in older (post-modal age) fertility. These two factors brought about a widening of the fertility curve. Prior to the fertility trough, variability in the timing of first birth had been increasing, but the area under the fertility curve had been declining because peak (modal) age-specific rates had been falling. These declines in peak rates were precipitous in Eastern Europe in the 1990s, but had also occurred to some extent in Western Europe. Around the time of the transition, peak rates began to stabilise: in some cases there were subsequent rises, but more often there was a flattening off and sometimes a modest ongoing decline. The transition from fall to rise in TFR1 occurred when the increase in the width of the curve, from the processes described above, could more than compensate for any further falls from a decline in peak rates. This explanation is valid for both Western and Eastern European countries, and for those which saw large changes in TFR1 rates and those where the rise was small. 
An overall conclusion is that although Western and Eastern countries historically have had very different patterns of timing of entry into motherhood, we are now seeing a convergence between countries, yet at the same time increasing variability within countries. The mean age at first birth is still rising in the majority of countries and it remains to be seen what the upper limit is; Goldstein (2006) suggests it could reach over 33. If women now feel increasingly free to start a family when economic conditions are favourable, then we could see more period booms and busts in fertility rates in the future, even if cohort rates remain stable.

\section{Acknowledgements}

Kryštof Zeman gave a great deal of practical help in developing the ideas presented and doing initial calculations. John Bongaarts and Tomás Sobotka commented on this paper. A summarised version of this paper was presented at the IUSSP Busan conference in 2013. 


\section{References}

Bongaarts, J. and Feeney, G. (1998) On the quantum and tempo of fertility. Population and Development Review 24(2): 271-291. doi:10.2307/2807974.

Bongaarts, J. and Sobotka, T. (2012). A Demographic Explanation for the Recent Rise in European Fertility, Population and Development Review 38(1): 83-120. doi:10.1111/j.1728-4457.2012.00473.x.

Burkimsher, M. (2011). Modelling biological birth order and comparison with census parity data in Switzerland. 2011. A report to complement the Swiss data in the Human Fertility Collection (HFC). Rostock: Max Planck Institute for Demographic Research (MPIDR Technical Report 2011-005).

Frejka, T. (2012). The role of contemporary childbearing postponement and recuperation in shaping period fertility trends. Comparative Population Studies 36(4): 927-957.

Goldstein, J.R. (2006). How late can first births be postponed? Some illustrative population-level calculations. Vienna Yearbook of Population Research 4: 153165.

Goldstein, J.R., Sobotka, T., and Jasilioniene, A. (2009). The end of 'lowest-low' fertility? Rostock: Max Planck Institute for Demographic Research (MPIDR Working Paper 2009-029).

Kohler, H-P., Billari, F.C., and Ortega, J.A. (2006). Low fertility in Europe: Causes, implications and policy options. In Harris, F.R. (ed.) The baby bust: Who will do the work? Who will pay the taxes? Maryland, USA: Rowman \& Littlefield: 48109.

Kreyenfeld, M., Zeman, K., Burkimsher, M., and Jaschinski, I. (2012). Fertility Data for German-speaking Countries: What is the Potential? Where are the Pitfalls? Comparative Population Studies 36(2-3).

Lesthaeghe, R. and Permanyer, I. (2014). European sub-replacement fertility: trapped or recovering? Michigan: University of Michigan. (Population Studies Center Research Report 14-822).

McDonald, P. and Kippen, R. (2011). Forecasting Births. Canberra: Australian Bureau of Statistics 
Myrskylä, M., Goldstein, J.R., and Cheng, Y-H.A. (2013). New Cohort Fertility Forecasts for the Developed World: Rises, Falls, and Reversals. Population and Development Review 39(1): 31-56. doi:10.1111/j.1728-4457.2013.00572.x.

Rallu, J-L. and Toulemon, L. (1994). Period fertility measures: the construction of different indices and their application to France, 1946-89. Population, An English Selection 6: 59-94.

Sobotka, T. (2003). Tempo-quantum and period-cohort interplay in fertility changes in Europe. Evidence from the Czech Republic, Italy, the Netherlands and Sweden. Demographic Research 8(6): 151-213. doi:10.4054/DemRes.2003.8.6.

Sobotka, T. (2004). Postponement of childbearing and low fertility in Europe. [PhD thesis] Groningen:University of Groningen. 